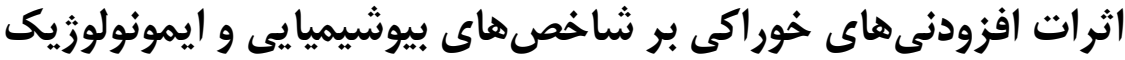 خون و عملكرد بلدر جين هاى زاينى (Coturnix coturnix Japonica)
}

\author{
توحيد وحدت يور

\begin{tabular}{|c|}
\hline استاديار فيزيولوزى، دانشكده علوم دامى و داميزشكى، واحد شبستر، دانشخاه آزاد اسلامى، شبستر، ايران \\
\hline تاريخ بذيرش: qV/ه/V \\
\hline
\end{tabular}

קكيده

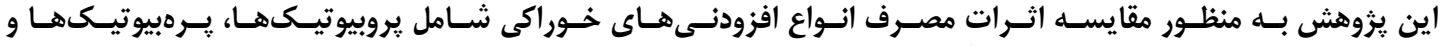

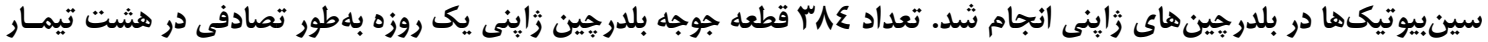

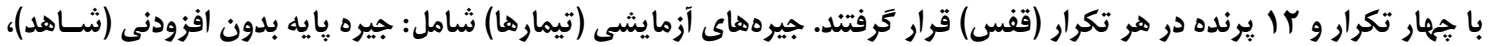

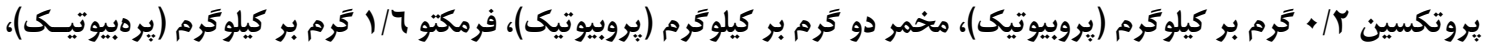

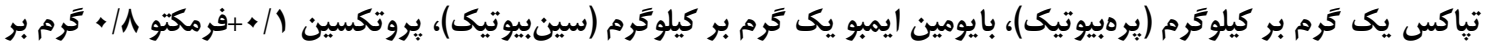

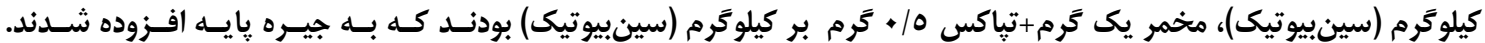

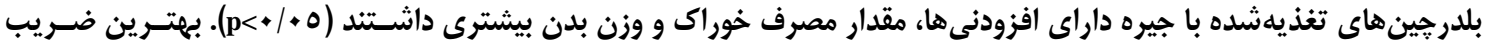

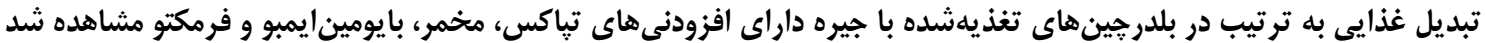

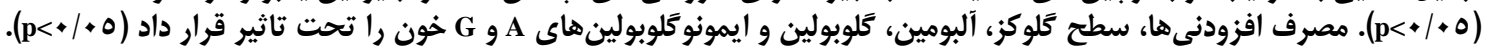

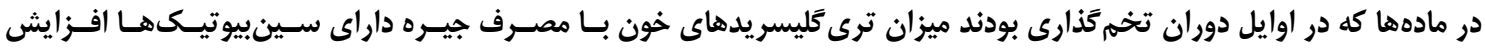

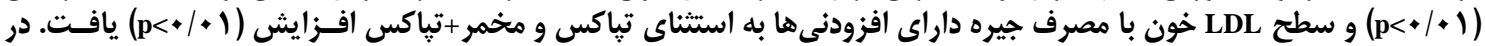

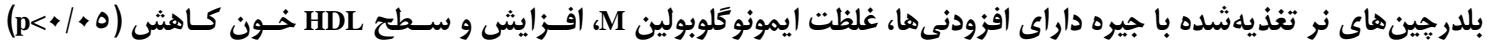

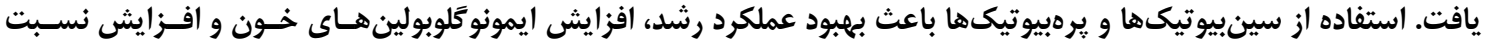

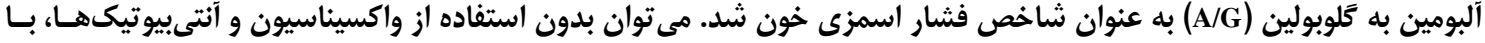

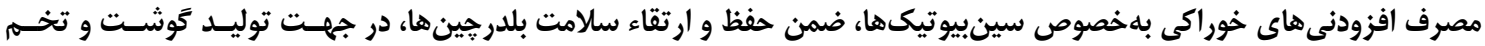
اركانيك به نحو مطلوبى اقدونى خورامى كرد.

وازههاى كليدى: يروبيوتيك، يرهبيوتيك، سينبيوتيك، خون، طيور

باعث افزايش بروز اسهال و مدفوع آبكى شده و با توليد بستر

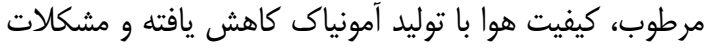

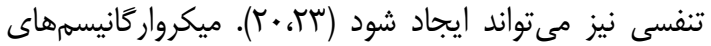

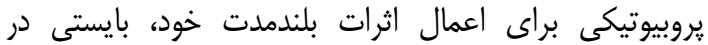

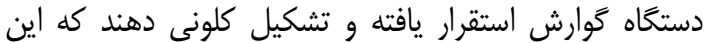

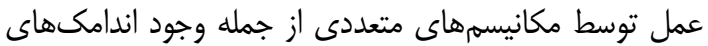

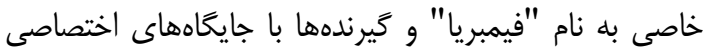

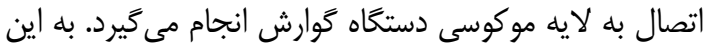

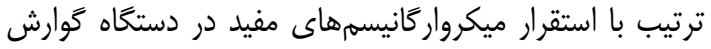

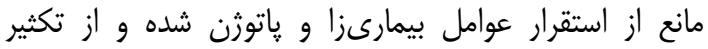

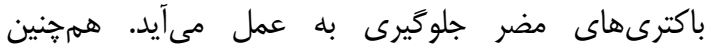

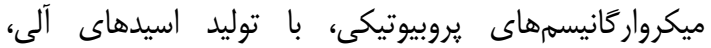

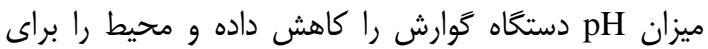

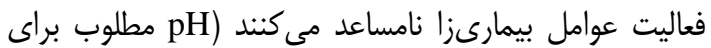

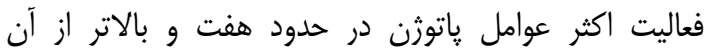

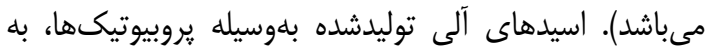

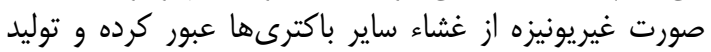

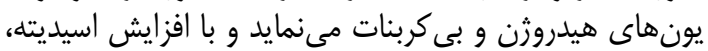

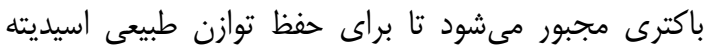

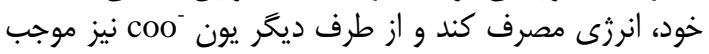

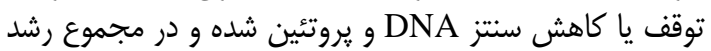
باكترى را كاهش مى كدهد (•) (1).
مقدمه

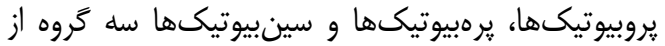

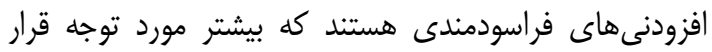

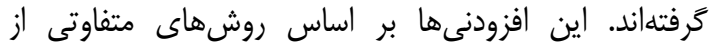

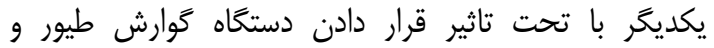

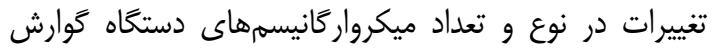

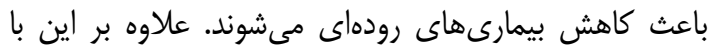

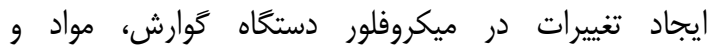

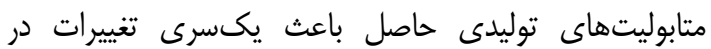

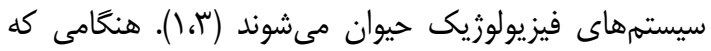

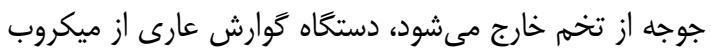

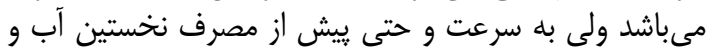

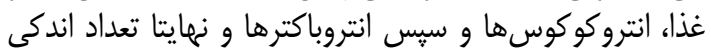

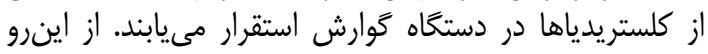

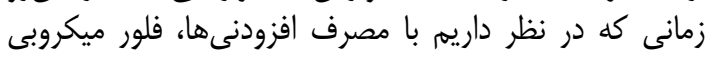

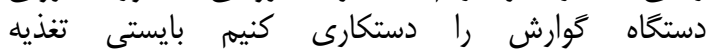

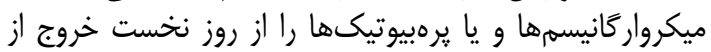

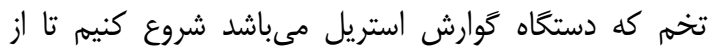

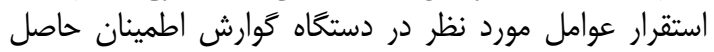

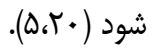

شرايط تنشزا موجب افزايش تكثير جندين نوع باكترى

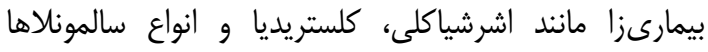
مىشود. علاوه بر تاثيرات اين اجرام بر فيزيولوزى بدئن بدن حيوان، 
توليد تخم، وزن تجمعى تخم براى هر يرنده و بهبود ضريب

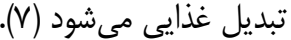

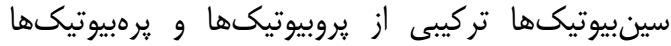

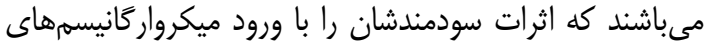

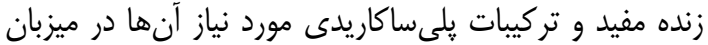

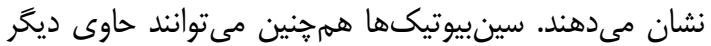

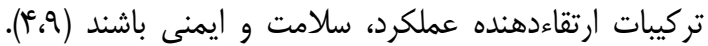

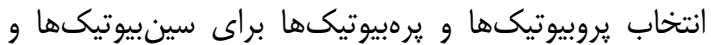

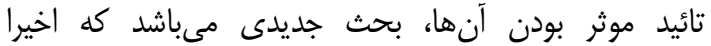

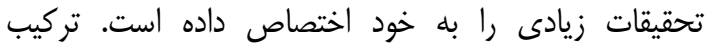

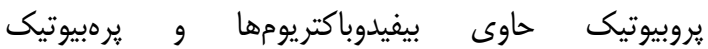
فروكتواليخوساكاريدها اثرات مثبت و سينرزيسمى از خوني خود نشان

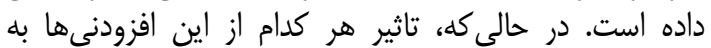

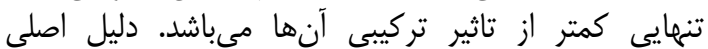

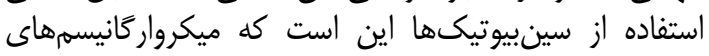

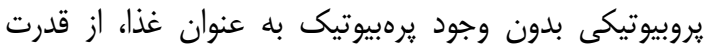

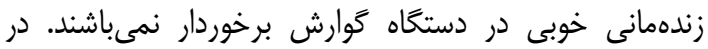

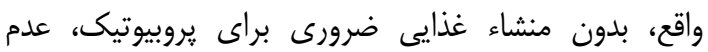

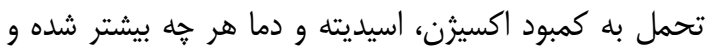

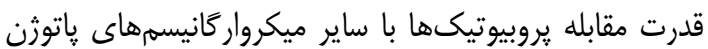

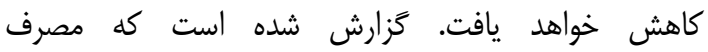
سينبيوتيكى تحت عنوان كامبيوتيك (ماكروتون) با تركيب

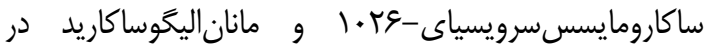

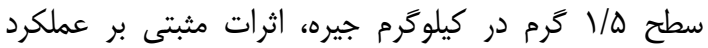

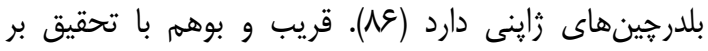

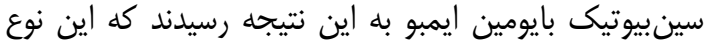

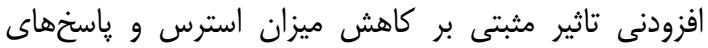

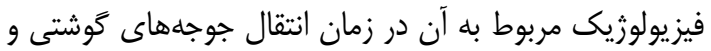

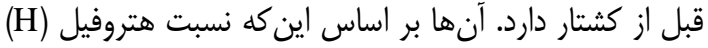

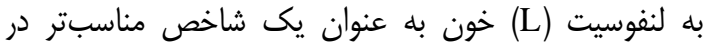

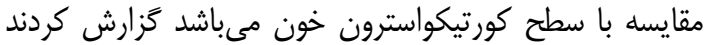

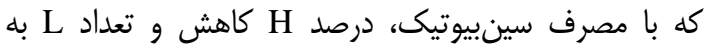

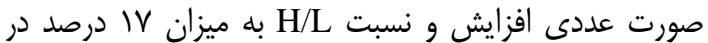

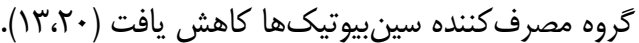

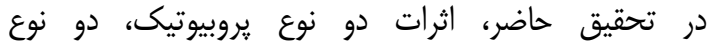

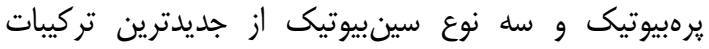

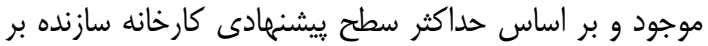

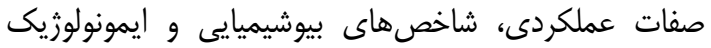

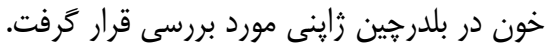

\section{مواد و روشها}

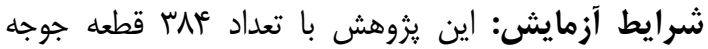

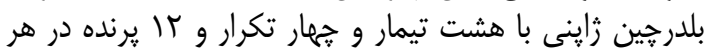
تكرار (قفس) در يك اتاق كنترلشده و و مجرهز

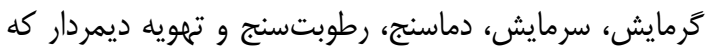

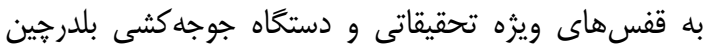

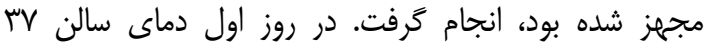
درجه سانتى

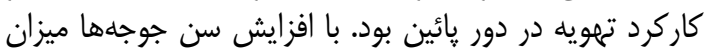

افزودنىهاى خوراكى مىتوانتد الكتروفيزيولوزى دستخاه

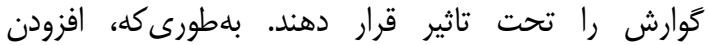

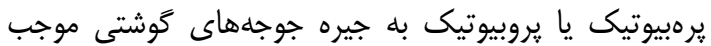

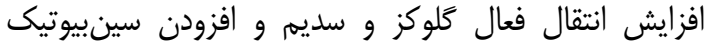

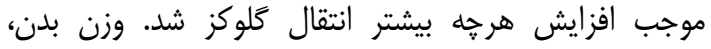

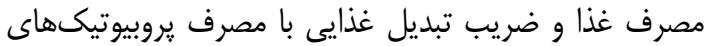

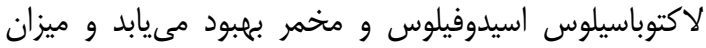

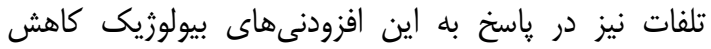

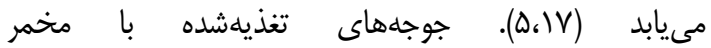

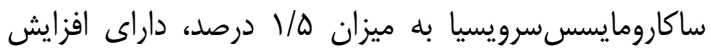

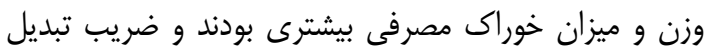

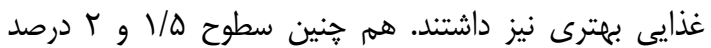

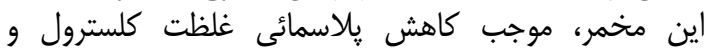

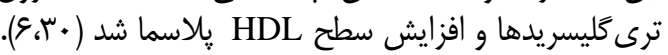

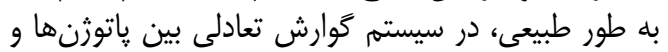

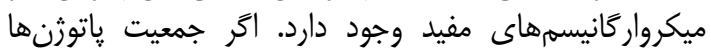

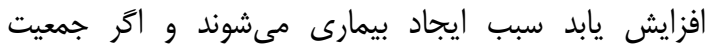

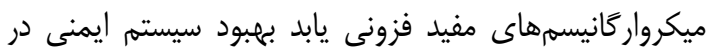

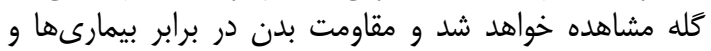

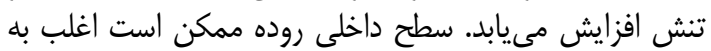

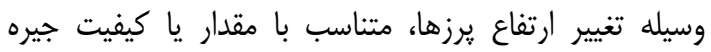

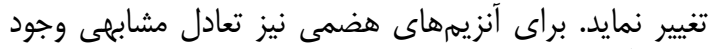

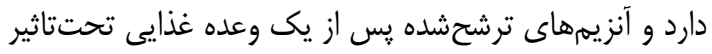

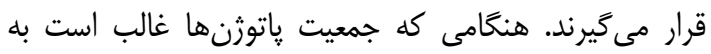

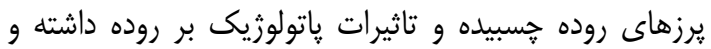

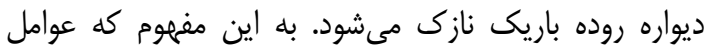

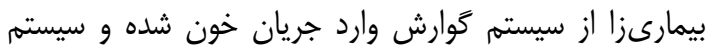

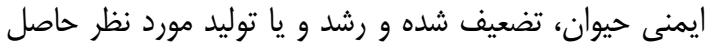

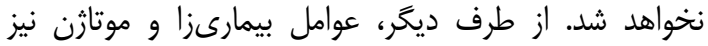

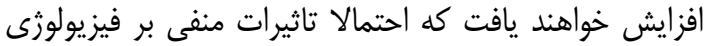
بلدن حيوان خواهند داشت (ع، أع).

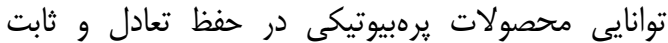

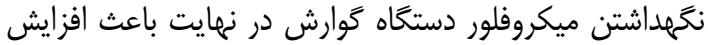

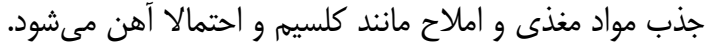

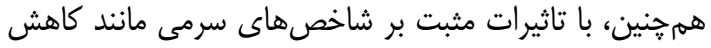

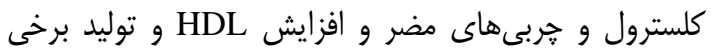

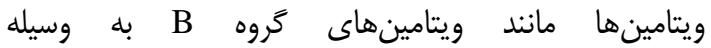

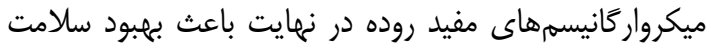

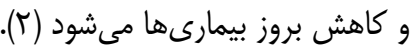

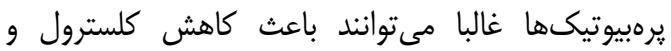

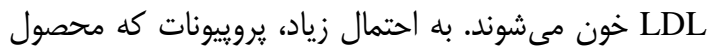

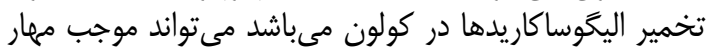

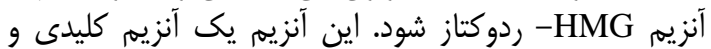

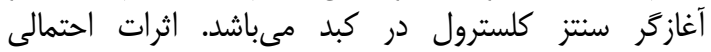

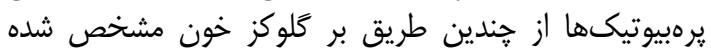

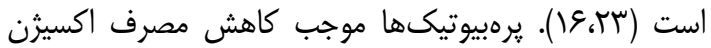

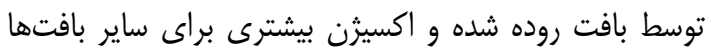

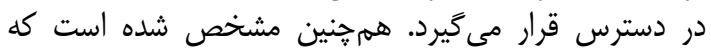

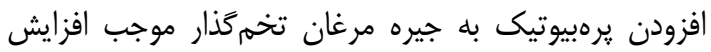


بهطور طبيعى نيز در روده يرندكان سالم وجود دارند كه در

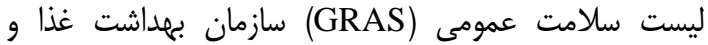

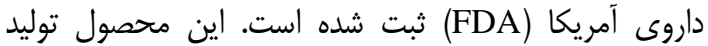

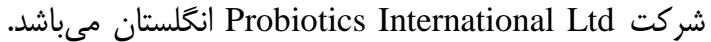

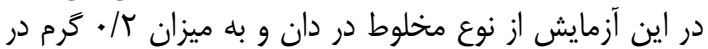
هر كيلوگرم جيره پِيايه استفاده شد.

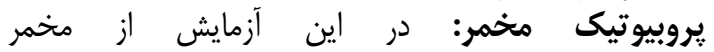

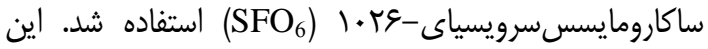

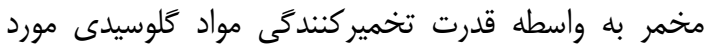

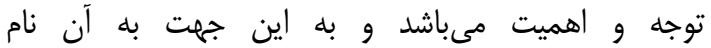

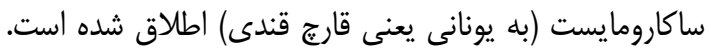

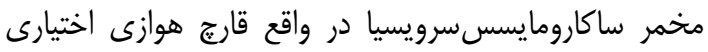

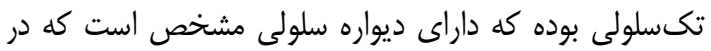

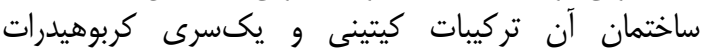

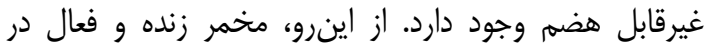

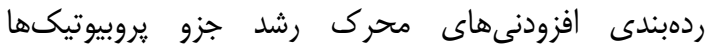
محسوب مىشود. مخمر استفاده شده در اين آزمايش آين توليد

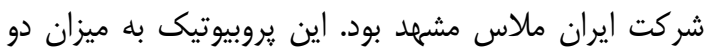

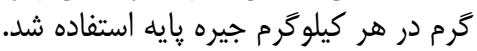

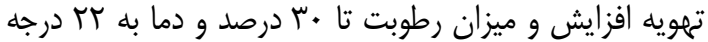
سانتى

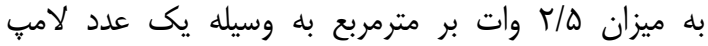
التهابى تامين شد.

فرمولاسيون جيره يايه: جيره گايايه بر اساس نيازهاى مواد

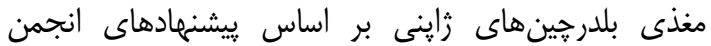

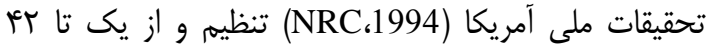

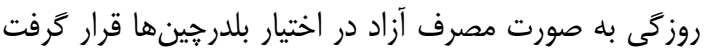

افزودنىهاى مورد استفاده: براى انجام اين آزمايش هفت

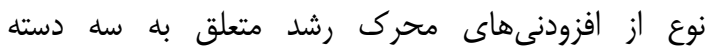

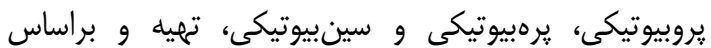

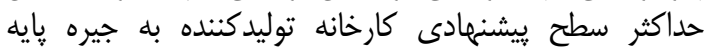

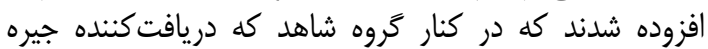

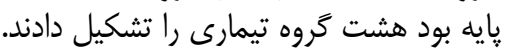

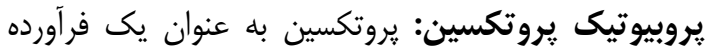

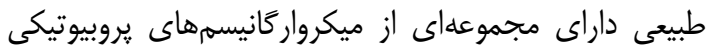

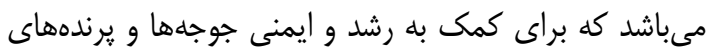

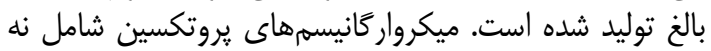

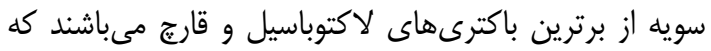

جدول ا - اجزاى جيره غذايى بايه و تركيبات محاسبه شده (بالانسشده بر اساس NRC) Table 1. Ingeredient of basel diet and computed compositions (Balanced according to NRC)

\begin{tabular}{|c|c|c|c|}
\hline مقدار & تركيبات محاسبهشده جيره & مقدار به درصد & نوع ماده غذايى \\
\hline ·. جr (كيلوكالرى/كيلوكرم) & انرزى قابل سوختوساز & $F N / A F$ & ذرت \\
\hline 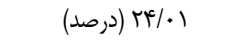 & يروتيين خام & - l & كنجاله سويا (بَ درصد بروتئين) \\
\hline ( • • (درصد) & كلسيم & $\Delta / \cdot \cdot$ & 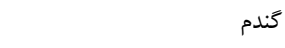 \\
\hline • • • (درصد) & فسفرقابل دسترس & $\Delta / .$. & كلوتن ذرت \\
\hline ه / • (درصد) & 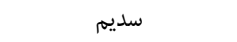 & $1 / \Delta V$ & يودر صدف \\
\hline F أ • (درصد) & 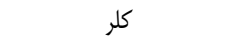 & $1 / r$. & روغن سويا \\
\hline (9) • (درصد) & يتاسيم & $\cdot|\wedge|$ & دى كلسيم فسفات \\
\hline • • • (درصد) & متيونين &.$/ T \Delta$ & بى كربنات سديم \\
\hline • • ا 1/درصد) & ليزين & $\cdot / r \Delta$ & مكمل مواد معدنى' , \\
\hline 1/19/• (درصد) & متيونين + سيستيئن &.$/ T \Delta$ & مكمل مواد ويتامينى' \\
\hline \multirow[t]{3}{*}{ זس/• (درصد) } & ترييتوفان &.$/ 1 V$ & ليزين منوهيدروكلرايد \\
\hline & &.$/ 19$ & نمك يددار \\
\hline & &.$/ 11$ & دى - ال - متيونين \\
\hline
\end{tabular}

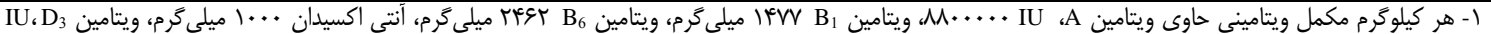

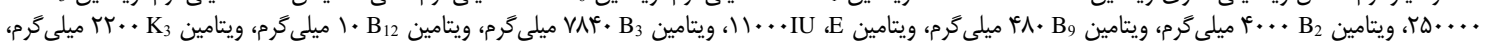

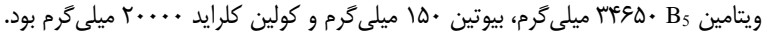

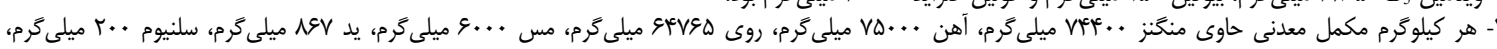

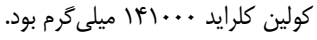

شركت توليدكننده سطح \&/ا گرم در هر كيلوگرم جيره پايه استفاده شد

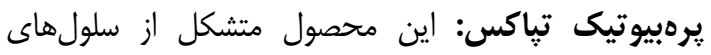

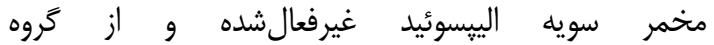

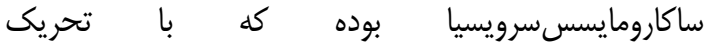

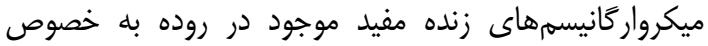

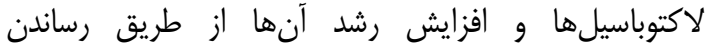

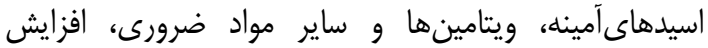
راندمان فرآيند هضم و جذب در دستخاه گوارش را را فراهم
يرهبيوتيك فرمكتو: اين :رهبيوتيك توليدى شركت امريكايى

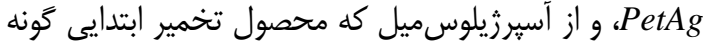

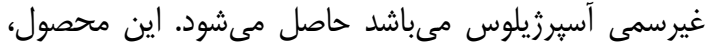

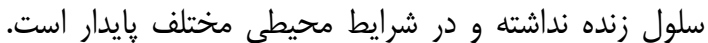

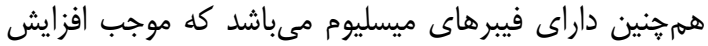

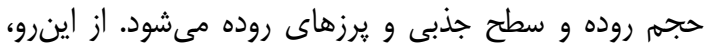

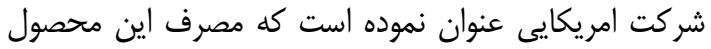

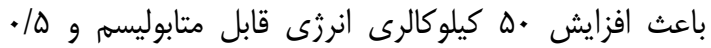

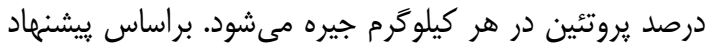




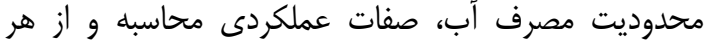

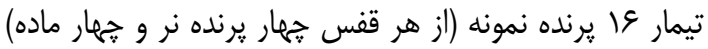

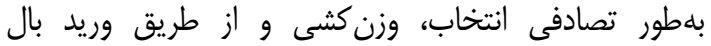

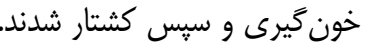
دستخاه و كيتهاى مورد استفاده جهت آناليز نمونههاى

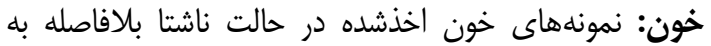

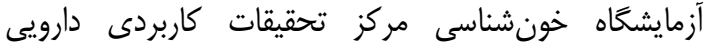

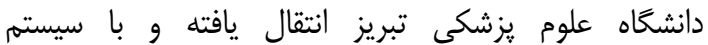

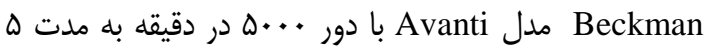
دقيقه سانتر يفيوز شده و سرمهاى حاصل با با سيستم اتوآناليزور

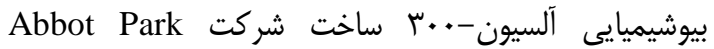

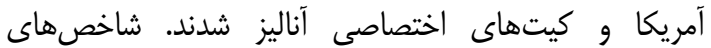

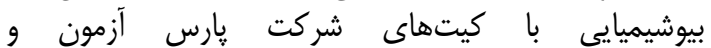

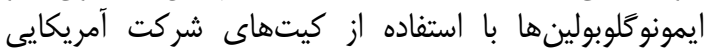

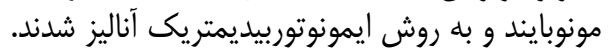

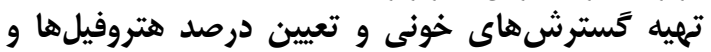
لنفوسيتهاى خون و نسبت

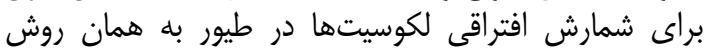

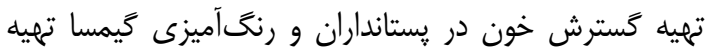

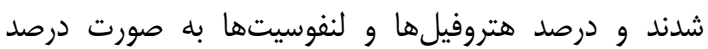
شمارش و نسبت H/L محاسبه شد. طرح آزمايشى و تجزيت المنايه دادهها: تجزيه واريانس و مقايسه

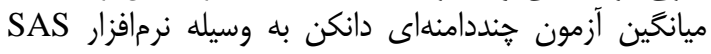

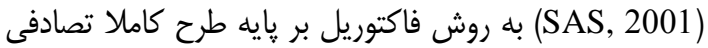

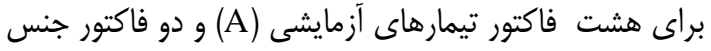

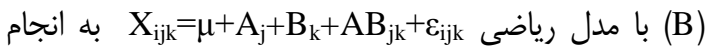

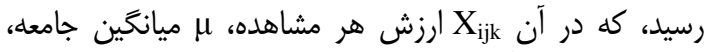

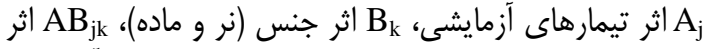

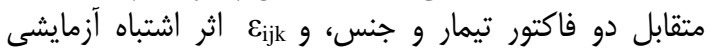

\section{نتايج و بحثث}

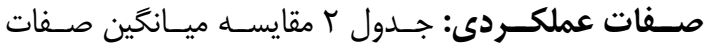

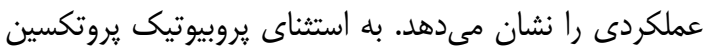

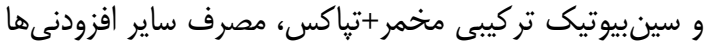

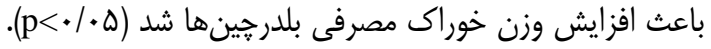

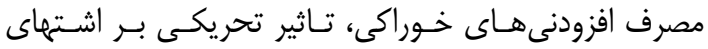

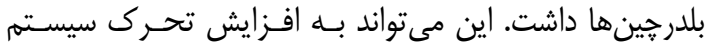

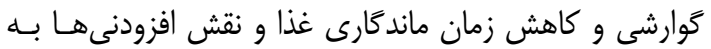

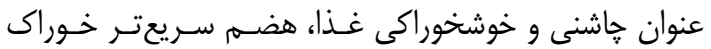

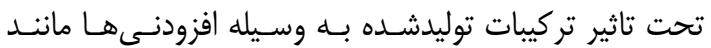

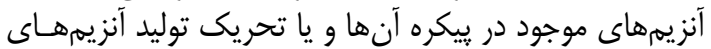

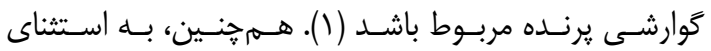

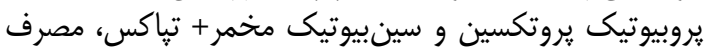

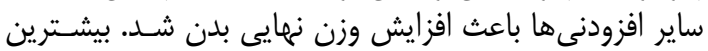

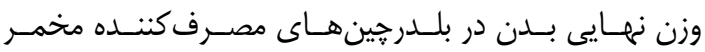

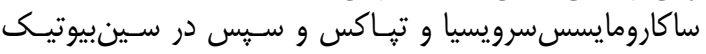

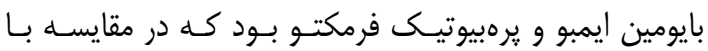

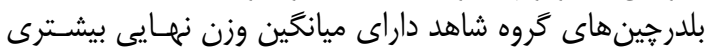

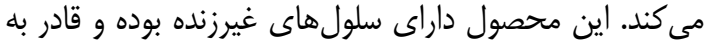

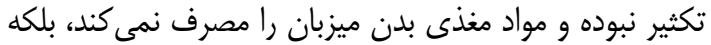

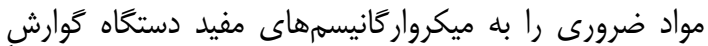
انتقال مىدهد. به طورى كه، اين ميكرواركانيسمهانها خصوصاً

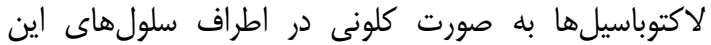

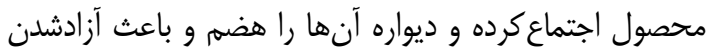

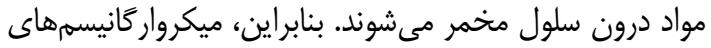

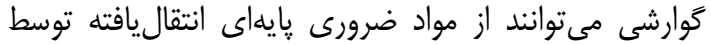

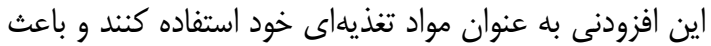

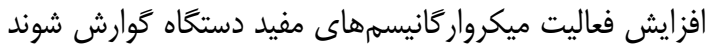

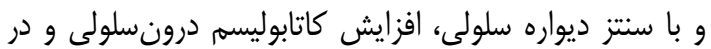

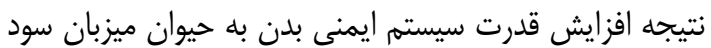

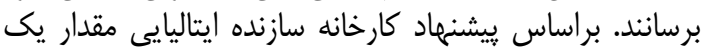

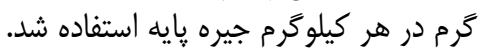

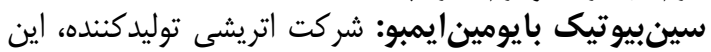

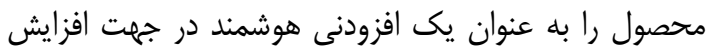

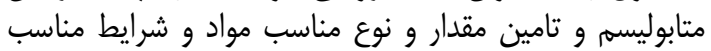

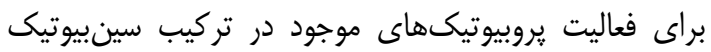

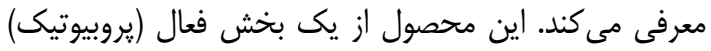

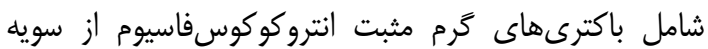

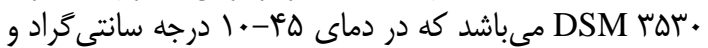

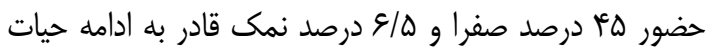

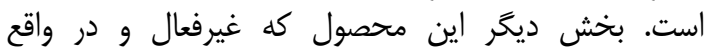

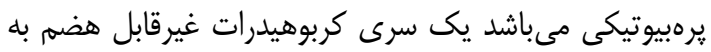

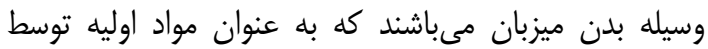

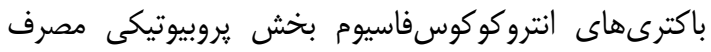

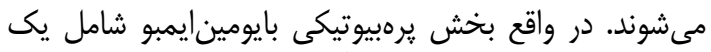

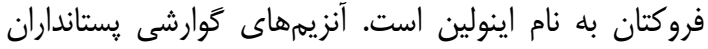

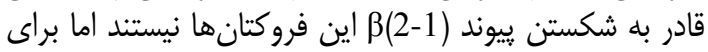

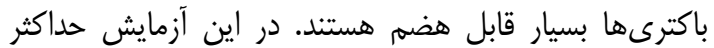

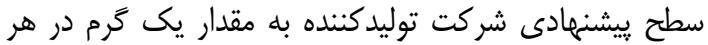

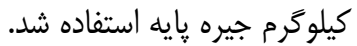

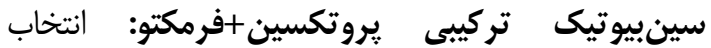

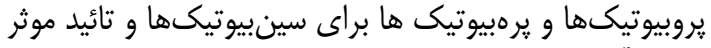

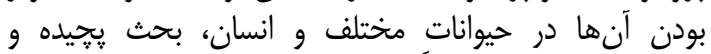

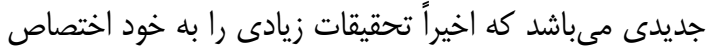

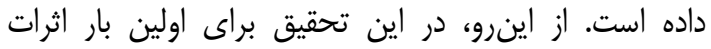

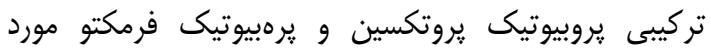

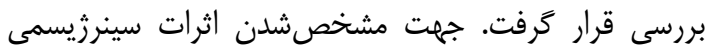

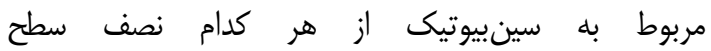

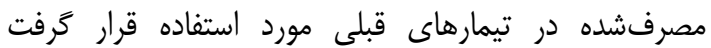

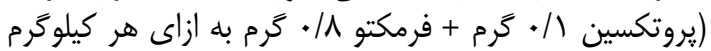

جيره بايه افزوده شد).

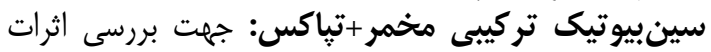

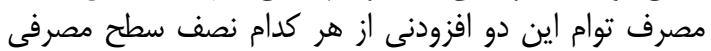

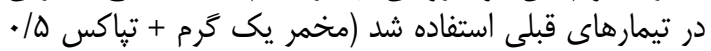

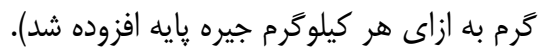

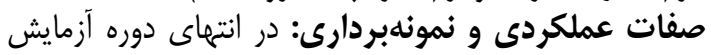

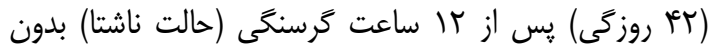


خصوص در نرها مىشود. استفاده از يكى نـوع يروبيوتيـك بــــا

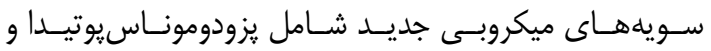

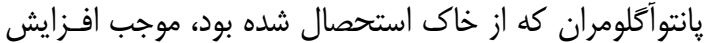

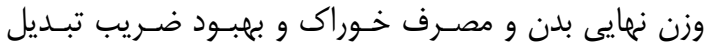

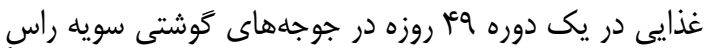

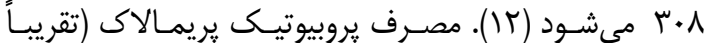

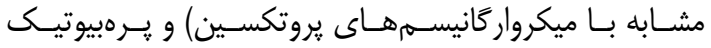

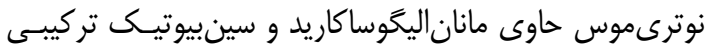

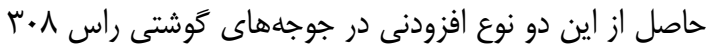

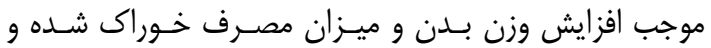

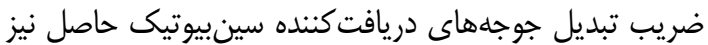

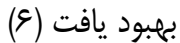

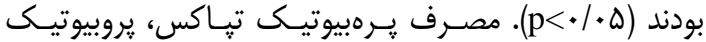

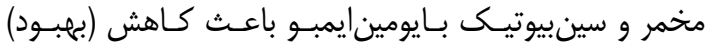

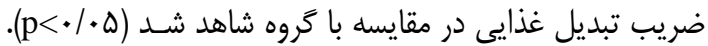

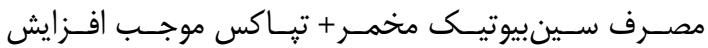
سينرزيسمى ضريب تبديل غذايى (تاثير منفى) در مقايسـهـ بـا بـا

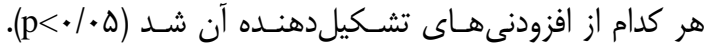

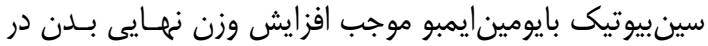

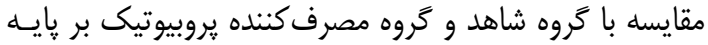

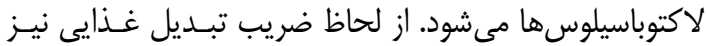

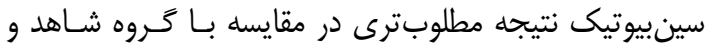

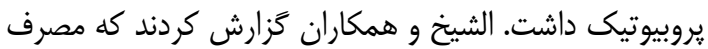

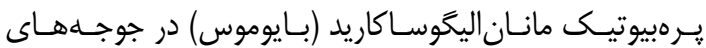

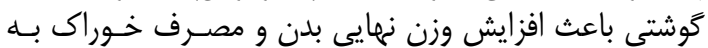

جدول r- ميانگين اثرات افزودنىها بر صفات عملكردى بلدريينهاى زاينى در انتهاى دوره آزمايش

Table 2. The mean effects of additives on functional traits of Japanese quails at the end of experimental

\begin{tabular}{|c|c|c|c|c|}
\hline بازده لاشه & 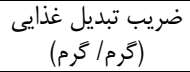 & 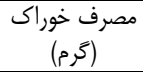 & 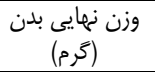 & صفت \\
\hline $9 \pi / r$. & $r / / f^{b c}$ & $99 \mathrm{~V} / .^{\mathrm{d}}$ & $r r / .^{c d}$ & شاهد (جيره پايه) \\
\hline $9 \Delta / \Delta$. & $r / 1 q^{a}$ & $v \cdot 1 / 1 \cdot^{c d}$ & $r r . / . d^{d}$ & جيره پايه+يروتكسين \\
\hline SD/F. & $r / \cdot \Delta^{\text {ef }}$ & $V \cdot 9 / . .^{a b}$ & rrr/... & جيره پايه+مخمر \\
\hline $99 / 1$. & $r / r^{\mathrm{cd}}$ & $v \cdot 9 / \cdot 1^{\mathrm{ab}}$ & $r r q / 1 .{ }^{b c}$ & جيره پايه+فرمكتو \\
\hline $94 / T$. & $r / \mu^{f}$ & $V \cdot r / . .{ }^{b c}$ & $r r r / .^{a}$ & جيره پايه+تياكس \\
\hline $90 / 1$. & $\mu / \lambda^{\mathrm{de}}$ & $v \cdot 9 / \cdot 1^{\mathrm{ab}}$ & $r r q / \cdot 1^{a b}$ & جيره پايه+بايومين \\
\hline $9 \Delta / q$. & $r / / r^{b c}$ & $v \cdot q / .^{a}$ & $r \leftarrow q / . .{ }^{b c}$ & جيره پايه+يروتكسين و فرمكتو \\
\hline $94 \%$ & $\Gamma / \Lambda b^{b c}$ & $v \cdot 1 / 1 \cdot^{\mathrm{cd}}$ & $T r T / / D^{\mathrm{cd}}$ & جيره بايه+مخمر و تِاكس \\
\hline .119 & $.1 \cdot \varphi^{c}$ & $.1 \cdot 4$ & . & 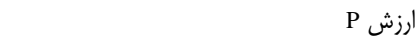 \\
\hline$\% / \cdot \Delta$ & .1 .9 & $\Delta / \Delta q$ & t/at & اشتباه معيار ميانگين (SEM) \\
\hline
\end{tabular}

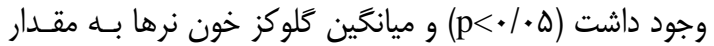

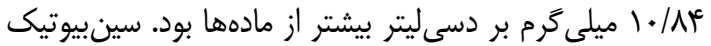

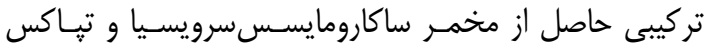

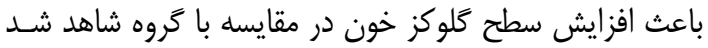

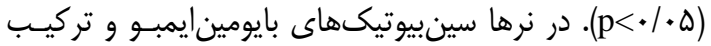

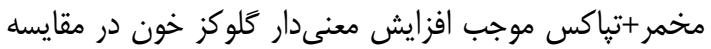

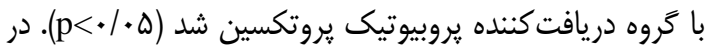

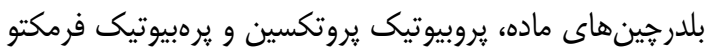

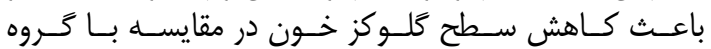

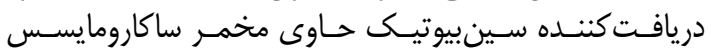

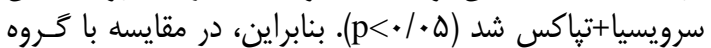

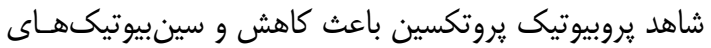

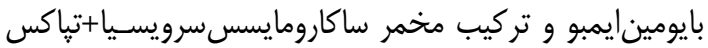

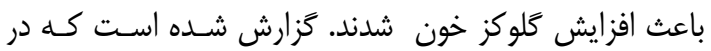

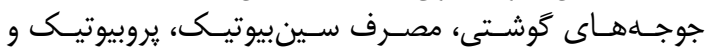

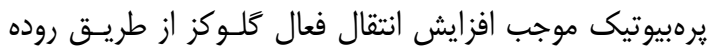

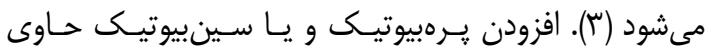

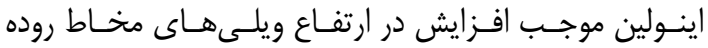

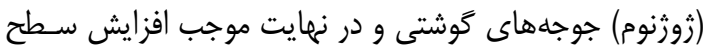

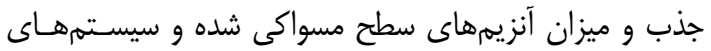

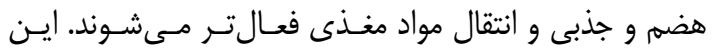

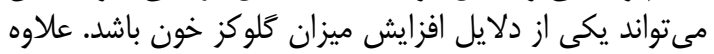

استفاده از مانان اليخوساكاريد (يرهبيوتيك) باعث افز ايش

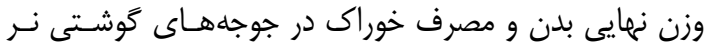

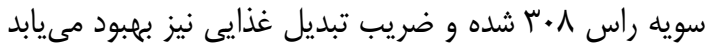

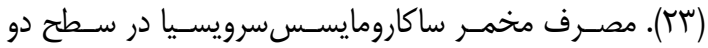

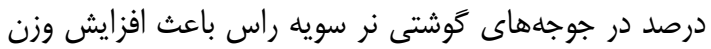

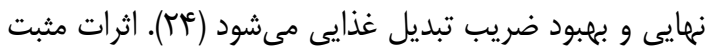

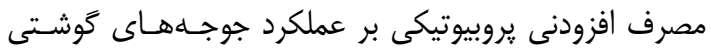

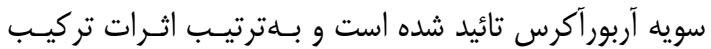

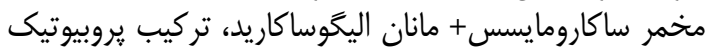

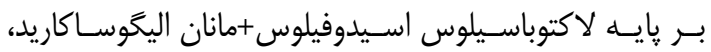

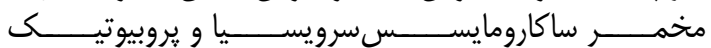

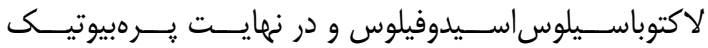

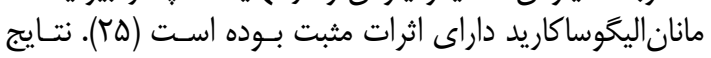

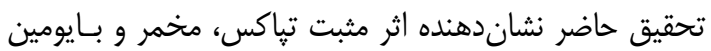

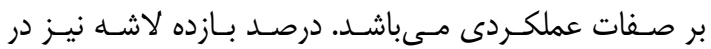

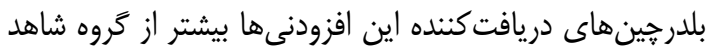

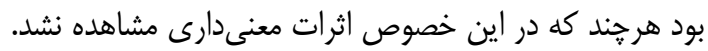

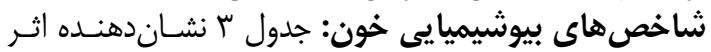

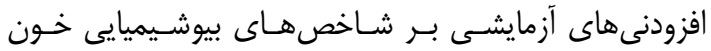

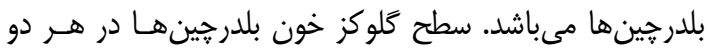

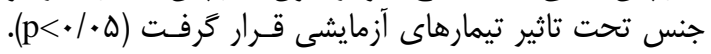

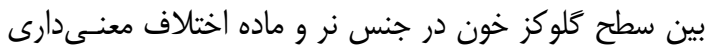


ضرورى و فيزيولوزيكى مىباشد (أ). بايومينايمبـو بــــ عنـوان

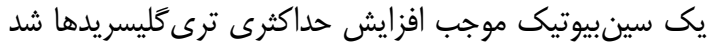

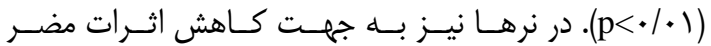

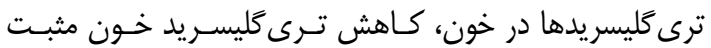

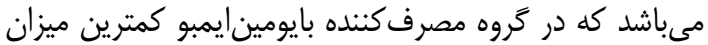

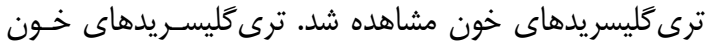

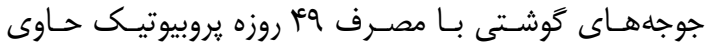

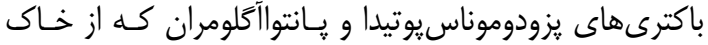

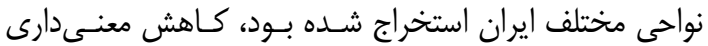

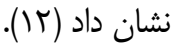

براين، مصرف يروبيوتيكها موجب افـزايش جـذب غيرفـــال

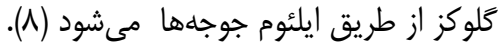

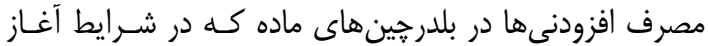

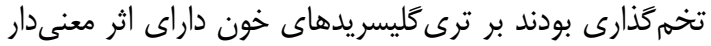

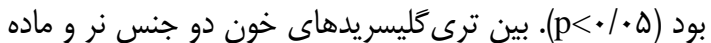

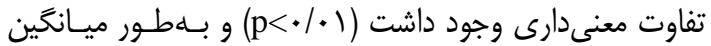

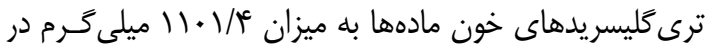

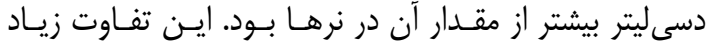

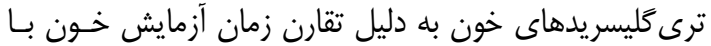

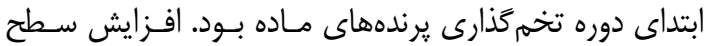

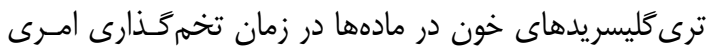

جدول ب- ميانكَين اثرات افزودنىها بر شاخصهاى بيوشيميايى خون بلدرجينهاى زاينى در انتهاى دوره آزمايش Table 3. The mean effects of additives on the blood biochemical indices of Japanese quails at the end of experimental

\begin{tabular}{|c|c|c|c|c|c|c|c|c|c|c|}
\hline \multicolumn{2}{|c|}{$\begin{array}{l}\mathrm{LDL} \\
(\mathrm{mg} / \mathrm{dl})\end{array}$} & \multicolumn{2}{|c|}{$\begin{array}{l}\mathrm{HDL} \\
(\mathrm{mg} / \mathrm{dl})\end{array}$} & \multicolumn{2}{|c|}{ كلسترول } & \multicolumn{2}{|c|}{$\begin{array}{c}\text { ترى گليسريدها } \\
\text { (mg/dl) }\end{array}$} & \multicolumn{2}{|c|}{ 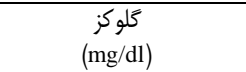 } & \multirow[t]{2}{*}{ تيمار } \\
\hline ماده & نر & ماده & نر & ماده & نر & ماده & نر & ماده & نر & \\
\hline$F T / T \Delta^{c}$ & $I r \cdot / r \Delta$ & $F \Psi / \Delta F$ & $11 \omega / 4 \Delta^{a}$ & $19 \vee / r$. & 每/.. & $\| r N / .{ }^{b c}$ & $q \vee / V \Delta$ & $r V \cdot / 0^{a b}$ & $r \Lambda \Delta / V \Delta^{\mathrm{ab}}$ & شاهد (جيره پايه) \\
\hline$r \mid q / .^{a}$ & $11 N / \Delta$. & $S V / F D$ & $9 Y / 9 \Delta^{\mathrm{a}}$ & $r q \mathrm{~V} / .$. & TrY/Q. & $\Delta M N / \neg \Lambda^{c}$ & $V \varepsilon / \Delta$. & $r \& \& / \omega \cdot{ }^{\mathrm{b}}$ & TET/D. ${ }^{\mathrm{b}}$ & جيره پايايه+يروتكسين \\
\hline $\mid f \Delta / . .{ }^{a b}$ & $I r \cdot / V \Delta$ & $\Delta r / F \Delta$ & $q \vee / r \Delta^{a}$ & $r q \mu / \mu$. & $r \pi / r \Delta$ & $V \backslash s / \Delta \cdot{ }^{b c}$ & $V Q / \Delta$. & $r \wedge \Delta / \Delta \cdot{ }^{a b}$ & $r V \Psi / \Delta \cdot{ }^{a b}$ & جيره پايه+مخمر \\
\hline$M \Delta / \Delta \cdot \cdot^{a}$ & ITN/TD & $\Delta N / F \Delta$ & $\Lambda \mathrm{V} / \mathrm{V} \Lambda^{\mathrm{a}}$ & $r \varepsilon \cdot 1 \Lambda$. & TET/TA & $998 / . . \mathrm{bc}$ & $\| F / r \Delta$ & $r \Delta N / . b^{b}$ & $r q T / \Delta \cdot \cdot^{a b}$ & جيره إيه+فرمكتو \\
\hline$\mu \kappa / D \cdot^{c}$ & IMN/D. & 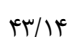 & $1 \cdot N / r 1^{\mathrm{a}}$ & $r$ r./A. & rrq/va & $119 \% / \cdot r^{\mathrm{bc}}$ & $\Lambda \kappa / v \Delta$ & $r \& 9 / \Delta .^{a b}$ & $r \wedge \mu / \Delta \cdot \cdot^{a b}$ & جيره پايه+تِاكس \\
\hline $191 / .^{a}$ & $1 \% \Delta / V \Delta$ & $\Delta T / Q \Delta$ & $\Delta V / \& \Delta^{b}$ & $\uparrow \wedge \Delta / \Delta$. & TTV/VQ & $r \mid \Lambda \varepsilon / \Lambda \cdot 0^{a}$ & SN/TD & $r \Lambda \Delta / V \Delta^{a b}$ & $r \cdot N / r \Delta^{a}$ & جيره بايه+بايومين \\
\hline $\mid \Delta N / \Delta \cdot \cdot^{a}$ & $\mid F T / V D$ & 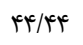 & $\Delta S / M^{b}$ & $r \cdot r / \Lambda$. & TTN/TD & $\mid V E \alpha / \Delta 0^{a b}$ & $111 / v \Delta$ & $r V / r \Delta^{a b}$ & $r \Lambda Y / \Delta .^{a b}$ & جيره پايه+يروتكسينوفرمكتو \\
\hline$\Delta \Psi / \Delta \cdot{ }^{b c}$ & $\mid f \Delta / \Delta$ & rN/99 & $\Lambda V / \Delta F^{a}$ & $r \Lambda \mu / \mu$. & rڤq/ब. & $\| f \& / \Lambda .{ }^{b c}$ & V৭/Q. & $r \cdot / r \Delta^{\mathrm{a}}$ & $r \cdot 9 / 0 \cdot{ }^{a}$ & جيره هايه+مخمر و تياكس \\
\hline $.1 \cdot 1$ &.$/ T \Delta$ & $\cdot / 90$ &.$/ . r$ &.$/ 1$. & $\cdot / \Delta F$ &.$/ .1$ & .119 & $.1 \cdot 4$ & . & 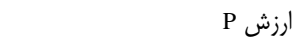 \\
\hline Tr/Ta & $r \cdot / r \Delta$ & $r q / .9$ & IN/Tr & $\| F Q / D F$ & $\Gamma \Delta / \mu$. & $199 / \wedge \Delta$ & $r \cdot / q \Lambda$ & $r I / v \Lambda$ & $r \Delta / r q$ & اشتباه معيار ميانكين (SEM) \\
\hline
\end{tabular}

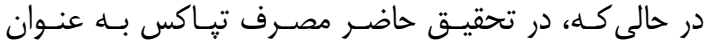

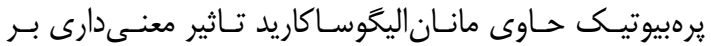

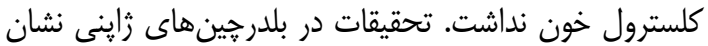

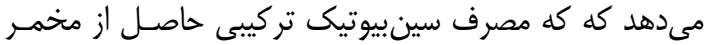

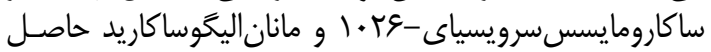

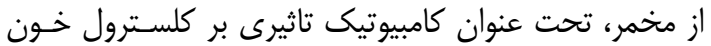

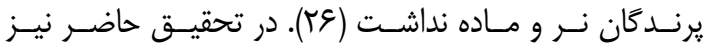

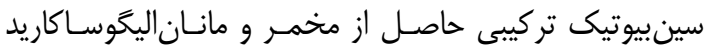

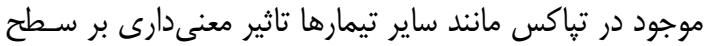

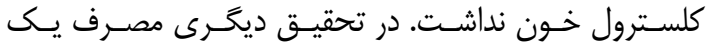

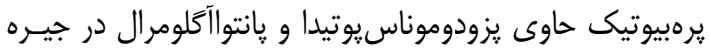

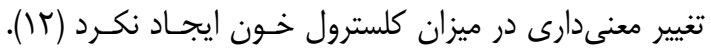

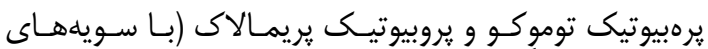

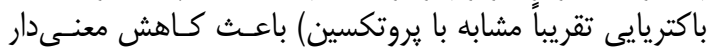

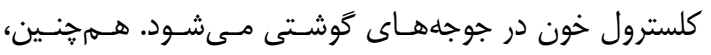

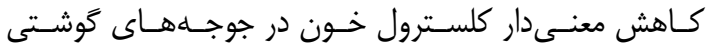

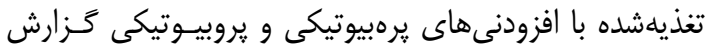

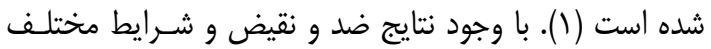

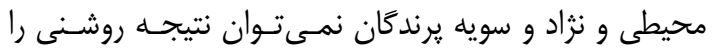

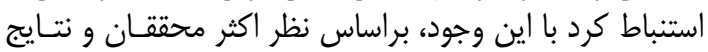

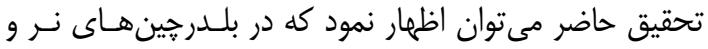

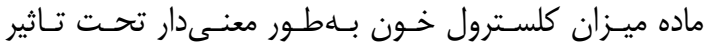

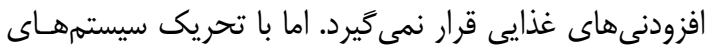

تغييرات مشابهى در گروههاى دريافت كننده يروبيوتيكها

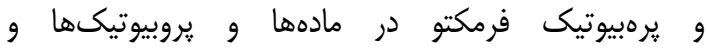

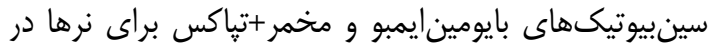

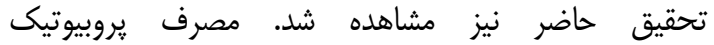

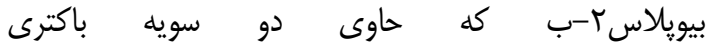
باسيلوسلشينيفورميس و باسيلوس سوبتيلس مى باشاشد تاثيرى

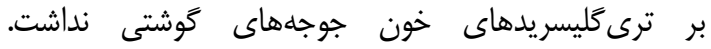

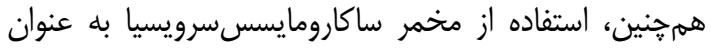

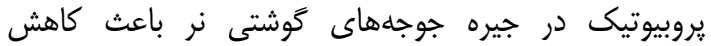

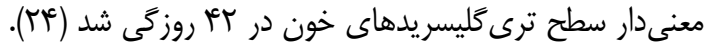

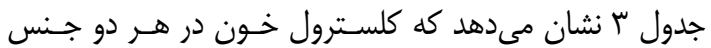

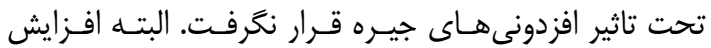

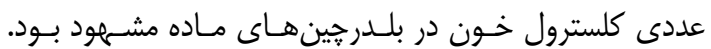

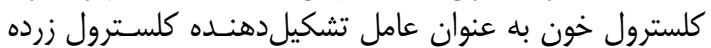

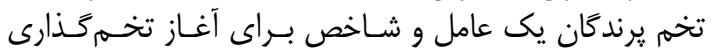

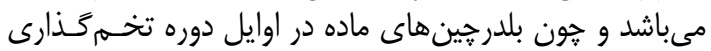

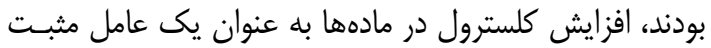

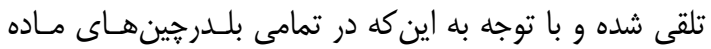

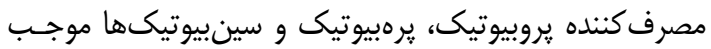

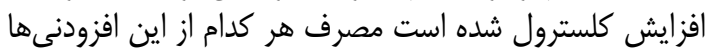

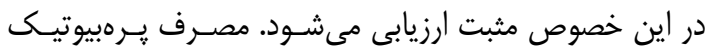

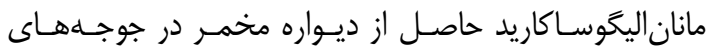

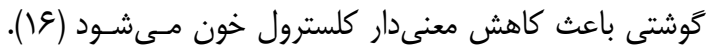




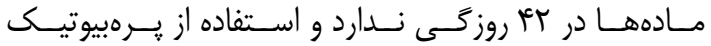

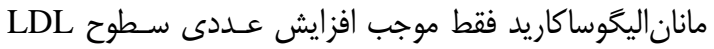

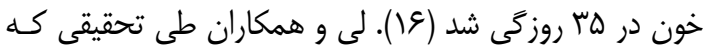

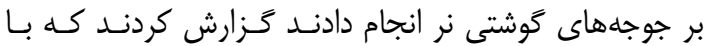

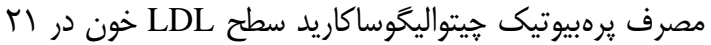

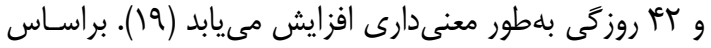

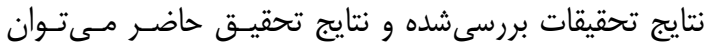

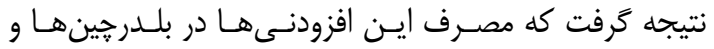

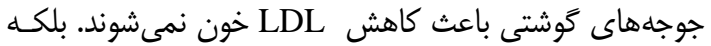

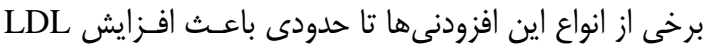

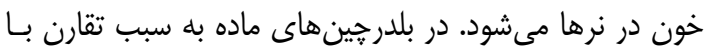

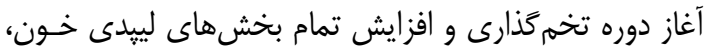

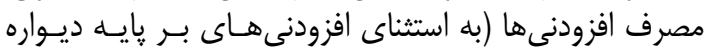

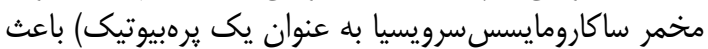
افزايش سطح LDL خون شدارس

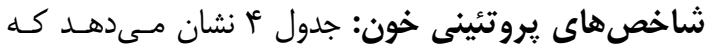

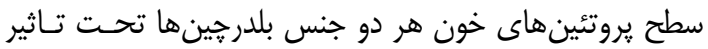

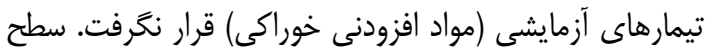

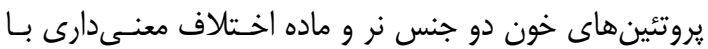

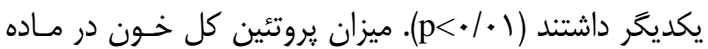

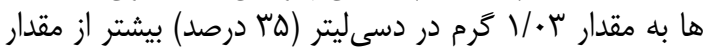

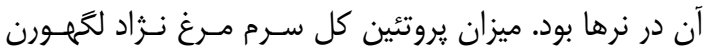

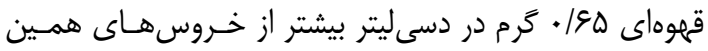

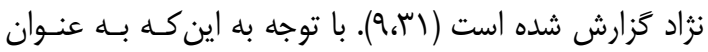

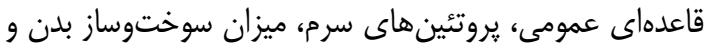

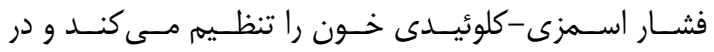

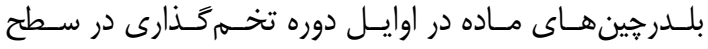

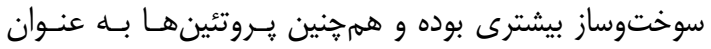

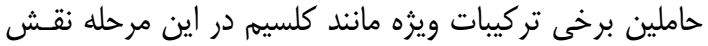

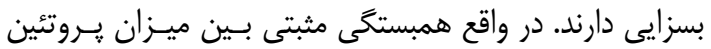

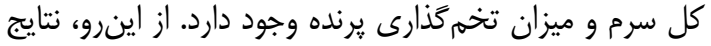

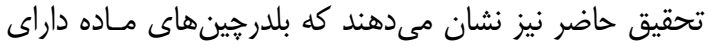

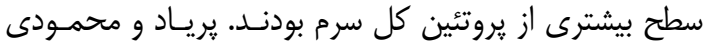

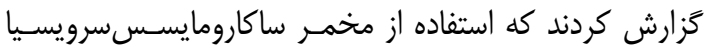

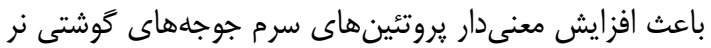

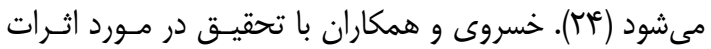

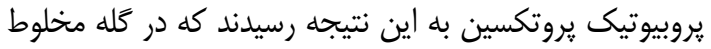

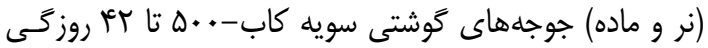

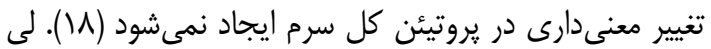

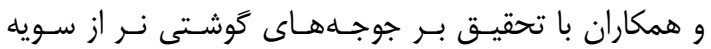

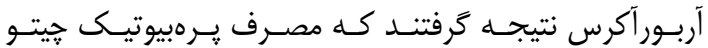

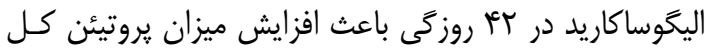

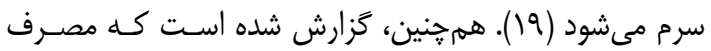

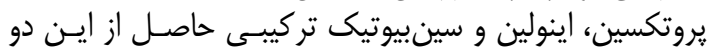

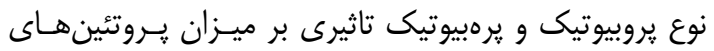

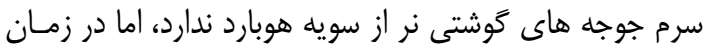

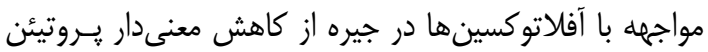

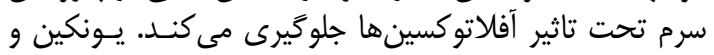

توليدمثلى بلدرجين هاى ماده، افزايش كلسترول جهت تحريك

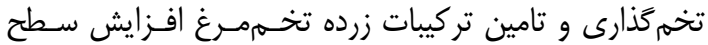

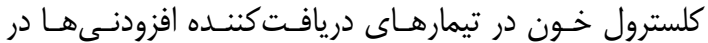
مقايسه با گروه شاهد وجود ديمارداي داشت.

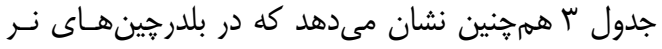

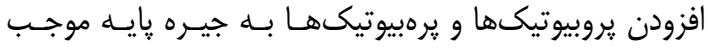

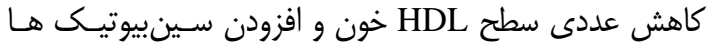

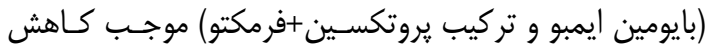

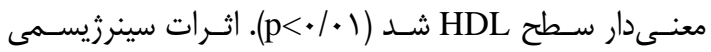

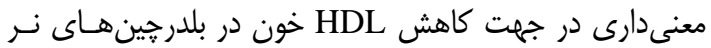

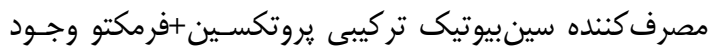

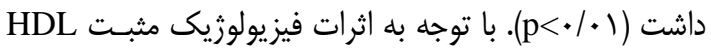

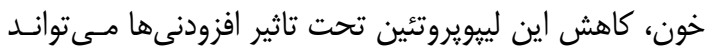

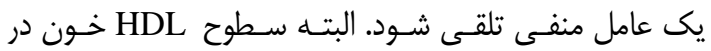

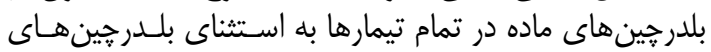

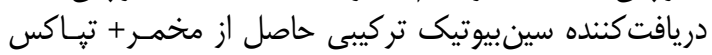

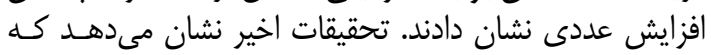

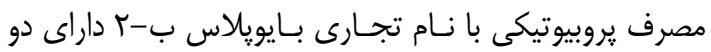

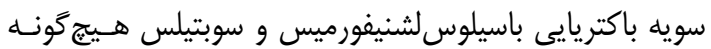

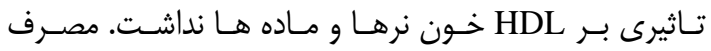

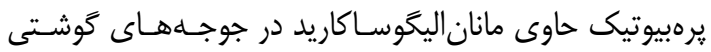

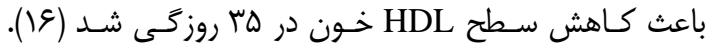

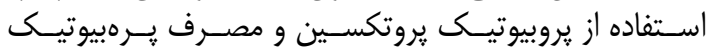

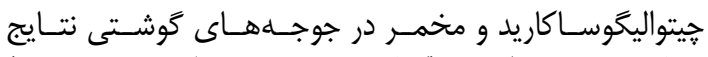

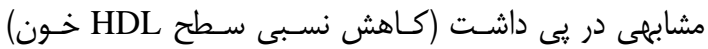

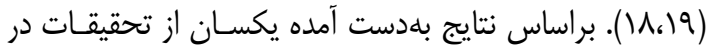

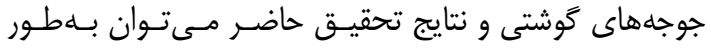

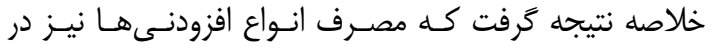

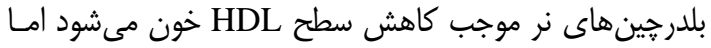

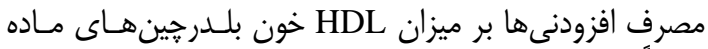
تقريباً بى تاثير مى مباشد.

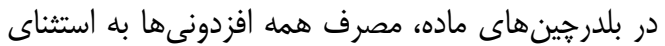

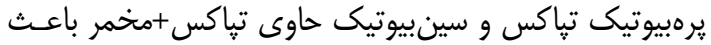

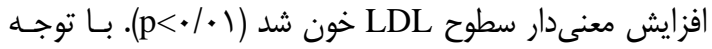

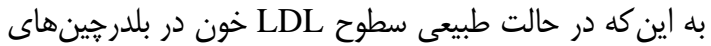

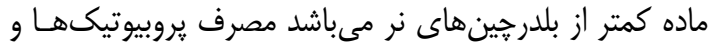

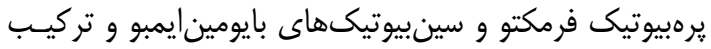

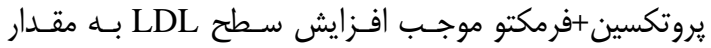

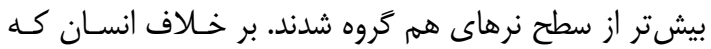

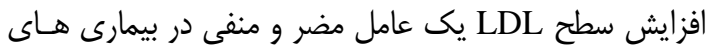

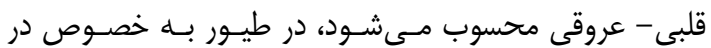

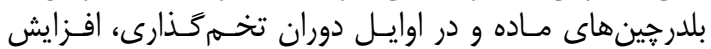

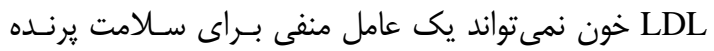

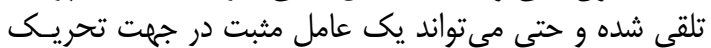

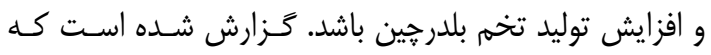

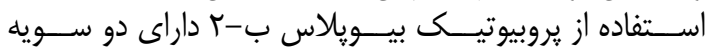

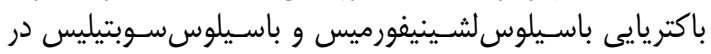
جيره جوجههاى كوشتى تاثير معنى دارى بر LDL خون نرها و 


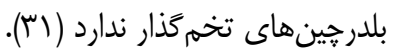

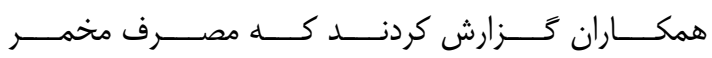

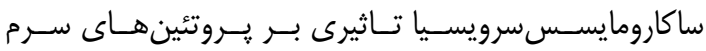

جدول f- ميانكَين اثرات افزودنىها بر شاخص هاى بروتئينى خون بلدرجينهاى زإينى در انتهاى دوره آزمايش Table 4. The mean effects of additives on blood protein indexes of Japanese quail at the end of experimental period

\begin{tabular}{|c|c|c|c|c|c|c|c|c|}
\hline \multicolumn{2}{|c|}{$\begin{array}{c}\text { A/G نسبت } \\
\text { (g/g) }\end{array}$} & \multicolumn{2}{|c|}{$\begin{array}{c}\text { كلوبولين (G/dl) } \\
\text { (g/dl }\end{array}$} & \multicolumn{2}{|c|}{$\begin{array}{c}\text { ألبومين (A/dl) } \\
\text { (g/d) }\end{array}$} & \multicolumn{2}{|c|}{ 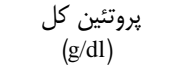 } & \multirow[t]{2}{*}{ صفت } \\
\hline ماده & نر & ماده & نر & ماده & نر & ماده & نر & \\
\hline $1 / \mu^{b}$ & $.194^{\mathrm{e}}$ & $1 / w^{a b}$ & $1 / q r^{a}$ & $r / l .{ }^{c d}$ & $1 / \Delta V^{c}$ & $r / \Lambda V$ & $r / r$. & شاهد (جيره پايه) \\
\hline $1 / . \mathrm{b}^{\mathrm{b}}$ & $1 / 4 r^{\text {de }}$ & $1 / 4 \Lambda^{a}$ & $1 / r \cdot{ }^{b c}$ & $1 / 9 r^{d}$ & $1 / \mathrm{V} \cdot \mathrm{bc}$ & $r / q$. & $r / q$. & جيره پايه+يروتكسين \\
\hline $1 / F T^{a b}$ & $1 / \Delta \gamma^{c d}$ & $1 / 4 r b c$ & $1 / 1 .{ }^{b c}$ & $r / .{ }^{c d}$ & $1 / v \cdot{ }^{b c}$ & $r / q$. & $r / v$. & جيره پايه+مخمر \\
\hline $1 / \Delta r^{\mathrm{ab}}$ & $1 / \Delta 9^{c d}$ & $1 / 9 a^{a b c}$ & $1 / \pi \mu^{a b c}$ & $r / r \omega^{\mathrm{bcd}}$ & $1 / 9 a^{a b}$ & $4 / \cdot 1$ & 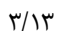 & جيره پايه+فرمكتو \\
\hline $1 / \mathcal{N}^{\mathrm{a}}$ & $r / \cdot \mu^{b c}$ & $1 / r^{b c}$ & $1 / \mu \cdot b c$ & $r / \Delta T^{a b}$ & $r / \cdot \Delta^{\mathrm{a}}$ & $r / N$ & $r / r$ & جيره پايه+تِاكس \\
\hline $1 / 4 \varepsilon^{a b}$ & $r / \pi r^{\mathrm{ab}}$ & $1 / \mathrm{v} \Lambda^{\mathrm{ab}}$ & $\cdot / \Lambda \mu^{c}$ & $r / \Delta r^{a b}$ & $1 / \wedge r^{\mathrm{ab}^{a b}}$ & TI/א & $r / 9 \Delta$ & جيره يايه+بايومين \\
\hline $1 / q r^{a}$ & $r / 99^{\mathrm{a}}$ & $1 / \pi \Delta^{c}$ & $\cdot / \lambda .^{c}$ & $r / \mu \mu^{a b c}$ & $r / \cdot \Lambda^{a}$ & $\Gamma / \Delta \Lambda$ & $r / \Lambda \Gamma$ & جيره پايه+يروتكسين و فرمكتو \\
\hline $1 / 99^{\mathrm{a}}$ & $1 / \varepsilon \Delta^{c d}$ & $1 / \mathbb{E}^{\mathrm{bc}}$ & $1 / r \Lambda^{a b}$ & $r / v \cdot^{a}$ & $r / \cdot \mu^{a}$ & $\kappa / \kappa$ & $r / M$ & جيره بِايه+مخمر و تِاكس \\
\hline .1 .1 & $.1 \cdot 1$ & $.1 \cdot 4$ & $.1 \cdot 1$ & $.1 \cdot 1$ & $.1 \cdot 1$ & •/ l & $\cdot / r \Delta$ & 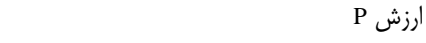 \\
\hline . & $\cdot / F \Delta$ & זr/. & .110 & $\cdot / r$. & 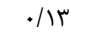 & $\cdot / V Q$ &.$/ \% \Delta$ & اشتباه معيار ميانگين (SEM) \\
\hline
\end{tabular}

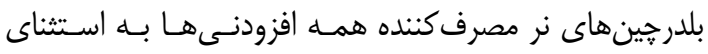

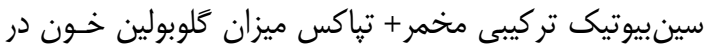

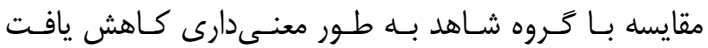

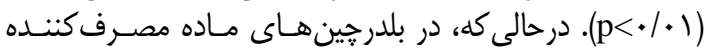

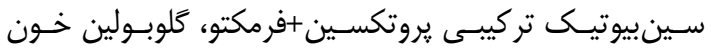

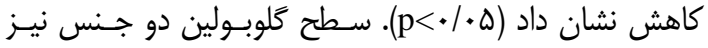

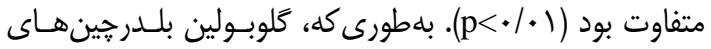

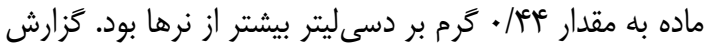

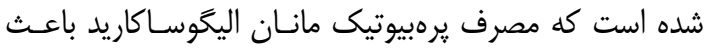

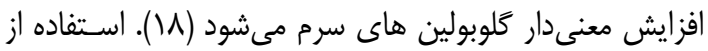

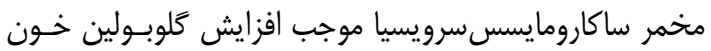

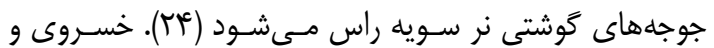

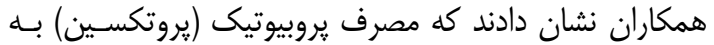

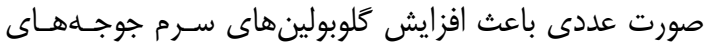

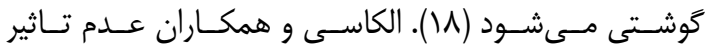

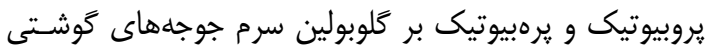
را كزارش كردند (1).

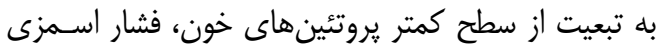

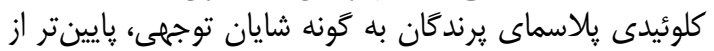

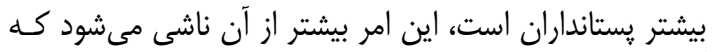

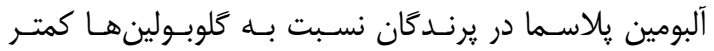

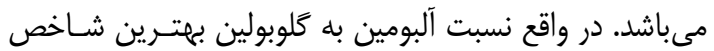

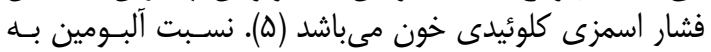

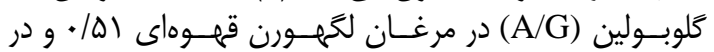

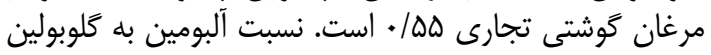

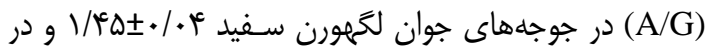

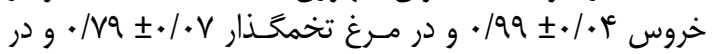

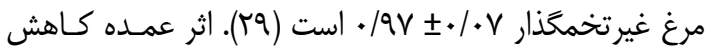

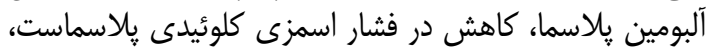

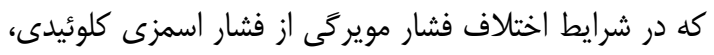

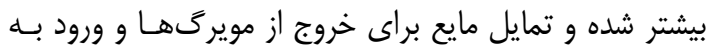

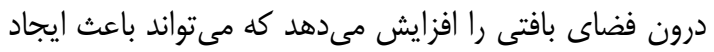

سطح آلبومين خون در هر دو جنس نر و ماده تحت تـاثير

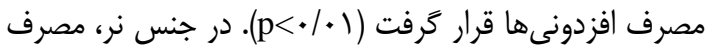

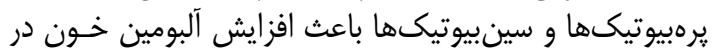

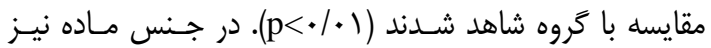

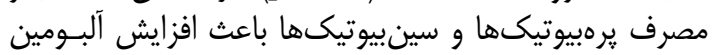

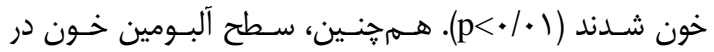

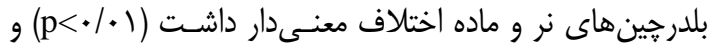

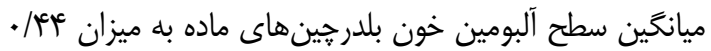

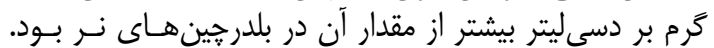

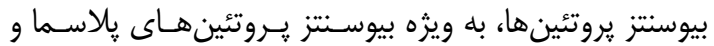

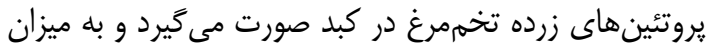

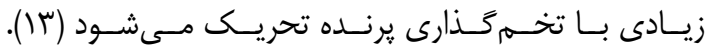

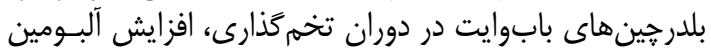

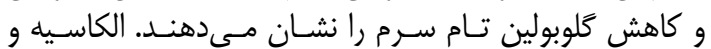

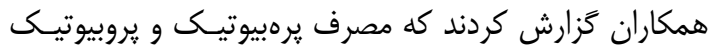

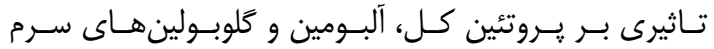

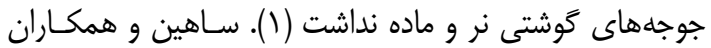

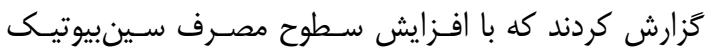

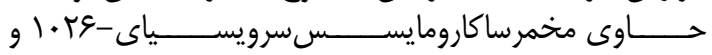

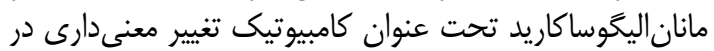

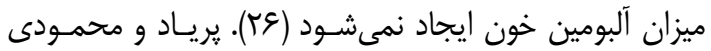

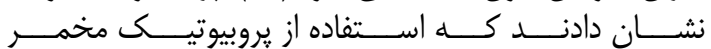

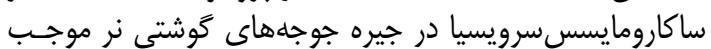

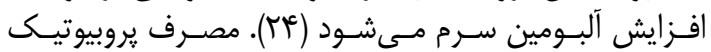

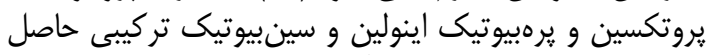

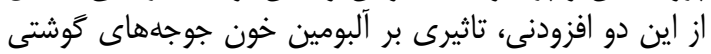

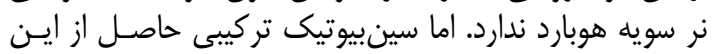

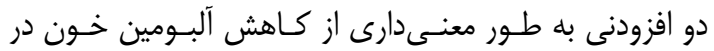

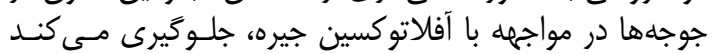

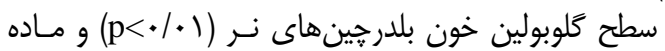

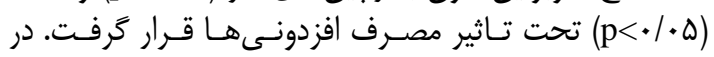


آنها از يكديخر با توجه به اختلاف موجـود در انتهـاى ثابـت

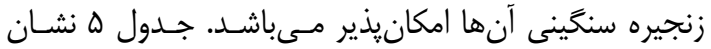

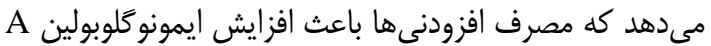

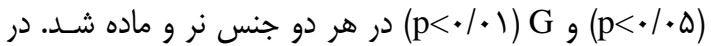

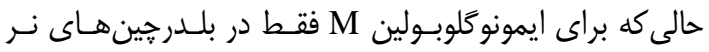

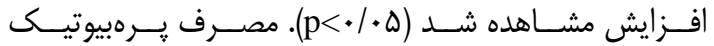

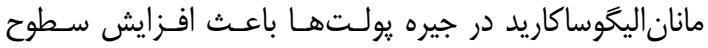

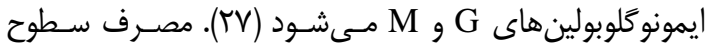

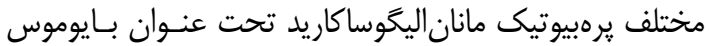

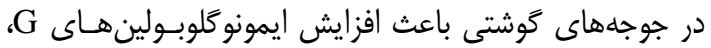
M

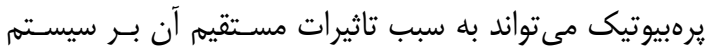

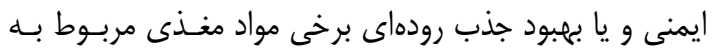

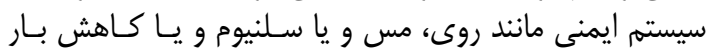

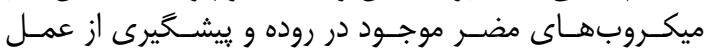

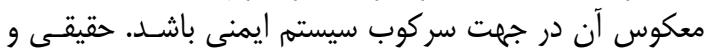

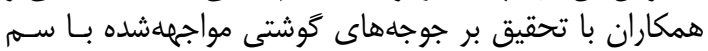

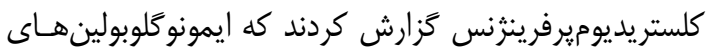

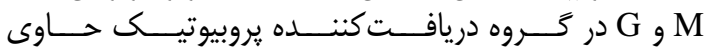

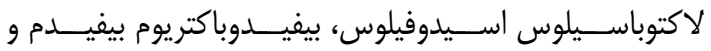

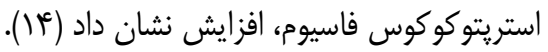

خيز يا آبآوردگى شود. به همين علت كاهش آلب آلبومين خــون،

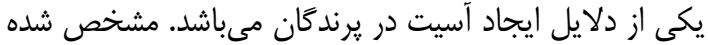

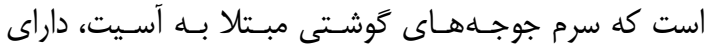
يروتئين پاسمايى كمتر از حد طبيعى مىباشد (19).

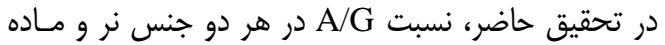

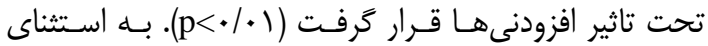

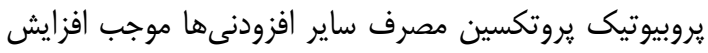

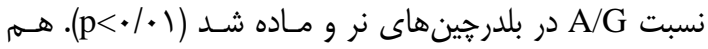

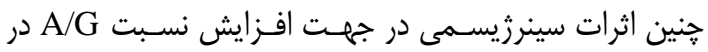

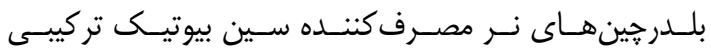

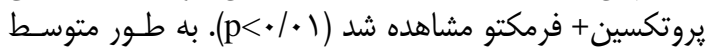

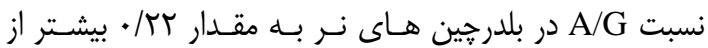

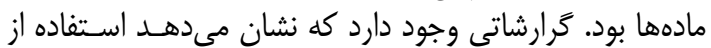

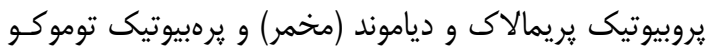

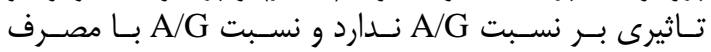

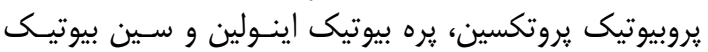

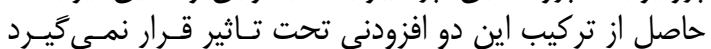

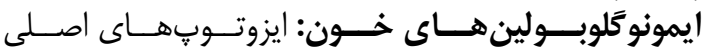

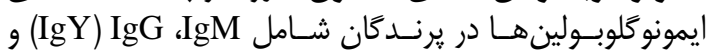

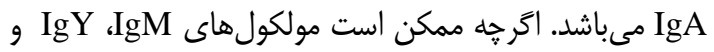

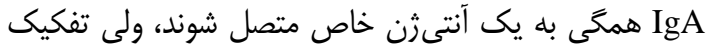

جدول ه- ميانكين اثرات افزودنىها بر شاخصهاى ايمونولوزيك خون بلدرجينهاى زإنى در انتهاى دوره آزمايش Table 5. The mean effects of additives on blood immunological indices of Japanese quails at the end of the experimental period

\begin{tabular}{|c|c|c|c|c|c|c|c|c|c|c|c|c|}
\hline \multicolumn{2}{|c|}{ 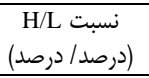 } & \multicolumn{2}{|c|}{$\begin{array}{c}\text { لنفوسيت درصد } \\
\end{array}$} & \multicolumn{2}{|c|}{ 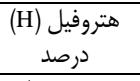 } & \multicolumn{2}{|c|}{$\begin{array}{c}\mathrm{Ig} \mathrm{G} \\
(\mathrm{mg} / \mathrm{dl})\end{array}$} & \multicolumn{2}{|c|}{$\begin{array}{c}\mathrm{Ig} \mathrm{M} \\
(\mathrm{mg} / \mathrm{dl})\end{array}$} & \multicolumn{2}{|c|}{$\begin{array}{c}\mathrm{Ig} \mathrm{A} \\
(\mathrm{mg} / \mathrm{dl})\end{array}$} & \multirow[t]{2}{*}{ صفت } \\
\hline 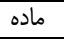 & نر & ماده & نر & ماده & نر & ماده & نر & 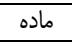 & نر & ماده & نر & \\
\hline . &.$/ T \Delta$ & 91 & VE & Mf & 19 & $\Delta / \Delta \cdot \cdot^{d}$ & $\Delta / \Delta F^{b c}$ & $T / T V$ & $r / r \Delta^{b}$ &.$/ \psi^{b}$ & 每/ & شاهد (جيره پاييه) \\
\hline (T) & 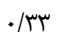 & $v^{\mu}$ & vr & 19 & זr & $\Delta / \Delta \Lambda^{c d}$ & $\Delta / \mathcal{E V}^{\mathrm{c}}$ & T\&/T & $r / s \Delta^{a}$ & $\cdot / v^{b}$ & $\cdot / \pi r^{a b}$ & جيره هايه+يروتكسين \\
\hline.$/ T \Lambda$ &.$/ M$ & v & ז & $r$. & If & $\Delta / \varsigma^{q} q^{d}$ & $\Delta / \kappa^{a b c}$ & $r / r q$ & T/rrab & $\cdot / r^{b}$ & $\cdot / \mathrm{r}^{\mathrm{ab}}$ & جيره پايه+مخمر \\
\hline 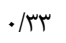 &.$/ T \Lambda$ & w & v) & iv & re & $\Delta / V^{a b c}$ & $\Delta / q^{b c}$ & $r / \uparrow Q$ & $r / s \lambda^{a}$ & $\cdot / \kappa^{a}{ }^{a}$ & $\cdot / \kappa^{\mathrm{a}}$ & جيره پايه+فرمكتو \\
\hline.$/ 4 V$ &.$/ \pi r$ & $v^{e}$ & $v^{m}$ & r. & r. & $\Delta / \& \Delta^{b c d}$ & $\Delta / q^{\mathrm{bc}}$ & $r / 4)$ & $r / \mu^{a b}$ & . & $\cdot / w v^{a b}$ & جيره پايه+تِاكس \\
\hline$\cdot / 19$ & $\cdot / T \Delta$ & VV & w & 10 & 11 & $\Delta / \Lambda r^{\mathrm{a}}$ & $\Delta / \wedge \gamma^{\mathrm{a}}$ & T/4 & $r / r^{\mathrm{a}}$ & $\cdot / \kappa \Delta^{\mathrm{a}}$ & $\cdot / \kappa \mu^{a}$ & جيره پايه+بايومين \\
\hline . &.$/ T \Delta$ & ve & w & iv & 19 & $\Delta / \wedge^{a b}$ & $\Delta / \& \Lambda^{a b}$ & $r / \mu$ & $r / r c^{a b}$ &.$/ \mu^{a b}$ &.$/ \mathrm{rq}^{\mathrm{ab}}$ & جيره پايه+يروتكسين و فرمكتو \\
\hline . & תr/ & VQ & ve & M & iv & $\Delta / V^{a b c}$ & $\Delta / v^{a b}$ & $r / \Psi r$ & $r / \sim^{a b}$ & $\cdot / \varphi^{a}$ & $\cdot / \kappa r^{a}$ & جيره بايه+مخمر و تباكس \\
\hline 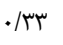 & $\cdot / \kappa a$ & $\cdot / \mathrm{VA}$ & $\cdot / 09$ &.$/ 81$ &.$/ D F$ & $.1 \cdot 1$ & $.1 \cdot 1$ &.$/ M$ & r & .1 .4 & $.1 \cdot 4$ & P ارزش P \\
\hline זו &.$/ 11$ & 9 & v & 9 & a & 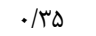 &.$/ T \Lambda$ & $\cdot / \mathrm{\Lambda}$ &.$/ 11$ & $\cdot 1 \cdot 1$ & $.1 \cdot \mathrm{V}$ & اشتباه معيار ميانگين (SEM) \\
\hline
\end{tabular}

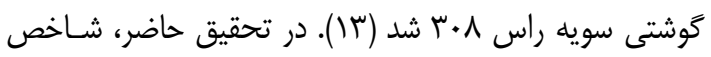

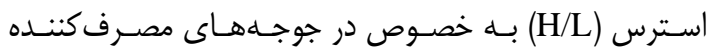
يروبيوتيك كاهش غيرمعنى دار نشان داد. نتايج تحقيق حاض داضـر

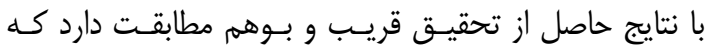

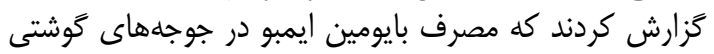

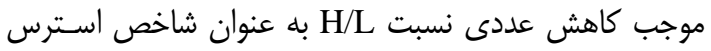

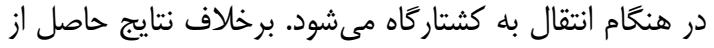

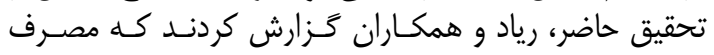

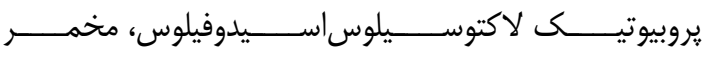

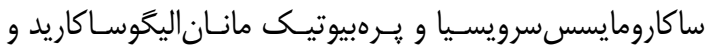

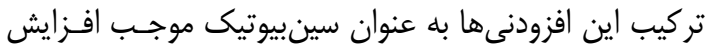

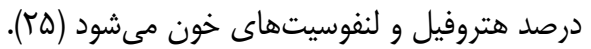

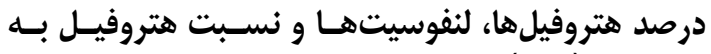

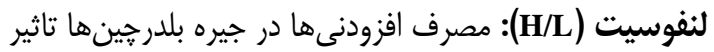

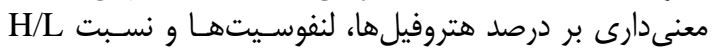

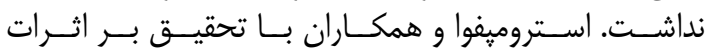

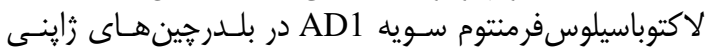

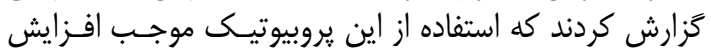

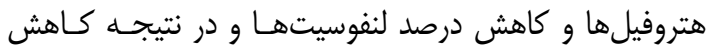

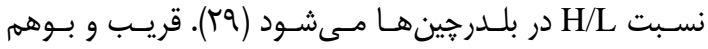

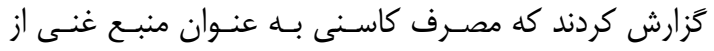

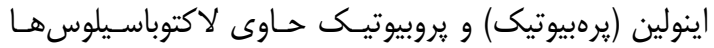

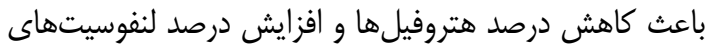

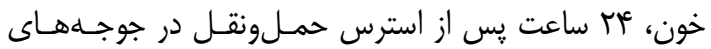


در بلدريين زإينى داراى مزاياى بيشترى بود. به استثناى

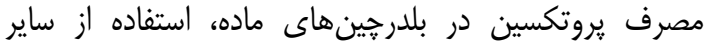

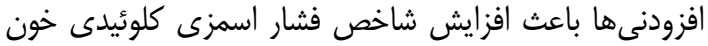

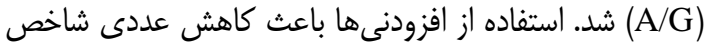

استرس (H/L) شد.

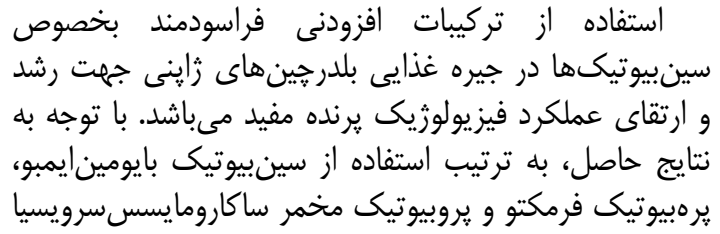

منابع

1. Al-Kassie, G.A.M., Y.M.F. Al-Jumaa and Y.J. Jameel. 2008. Effect of probiotic (Aspergillus Niger) and prebiotic (taraxacum officinale) on blood picture and biochemical properties of broiler chicks. International Journal of Poultry Science, 7: 1182-1184.

2. Ashayerizadeh, A., N. Dabiri, O. Ashayerizadeh, K.H. Mirzadeh, H. Roshanfekr and M. Mamooee. 2009. Effect of dietary antibiotic, probiotic and prebiotic as growth promoters, on growth performance, carcass characteristics and hematological indices of broiler chickens. Pakistan Journal of Biological Sciences, 12: 52-57.

3. Awad, W.A., K. Ghareeb, S. Abdel-raheem and J. Bohm. 2009. Effects of dietary inclusion of probiotic and synbiotic on growth performance, organ weights and intestinal histomorphology of broiler chickens. Poultry Science, 88: 49-55.

4. Bielecka, M., E. Biedrzycka and A. Majkowska. 2016. Selection of probiotics and prebiotics for synbiotics and confirmation of their in vivo effectiveness. Feed Research International, 35: 125-131.

5. Bishop, B. C. 2009. Animal models used in identifying gender-related differences, International Journal of Toxicology, 20: 153-160.

6. Bozkurt, M., K. Kucukyimaz, A.U. Cath and M. Cinar. 2009. The effect of single or combined dietary supplementation of Prebiotics, organic acid and probiotics on performance and slaughter characteristics of broilers. South African Journal of Animal Science, 39: 197-205.

7. Chen, K.L., W.L. Kho, S.H. You, R.H. Yeh, S.W. Tang and C.W. Hsieh. 2009. Effects of bacillus subtilis var. natto and saccharomyces cerevisiae mixed fermented feed on the enhanced growth performance of broilers. Poultry Science, 88: 309-315.

8. Chichlowski, M., J. Croom, R. Qui, B.W. McBride and M.D. Koci. 2008. Direct fed microbial Perimalac supplementation and jejuna glucose and proline transport in broiler chickens. International Journal of Poultry Science, $7: 1163-1166$.

9. De Vrese, M. and J. Schrezenmeir. 2008. Probiotics, prebiotics and synbiotics. Advances in Biochemical Engineering/Biotechnology, 111: 1-66.

10. El-Husseiny, O.M., A.G. Abdallah and K.O. Abdel-Latif. 2008. The influence of biological feed additives on broiler performance. International Journal of Poultry Science, 7: 862-871.

11. El-Sheikh, A.M.H., E.A. Abdalla and M.M. Hanafy. 2009. Study on productive performance, hematological and immunological parameters in a local strain of chickens as affected by mannan oligosaccharide under hot climate conditions. Egyptian Poultry Science, 29: 287-305.

12. Ghaderi Jouybari M., V. Rezaeipour, M. Mohammadzadeh Nagharchi, M.R. Taghizadeh and N. Dehpanah. 2009. The effect of novel probiotic on blood parameters and performance in broiler chickens. Journal of Cell and Animal Biology, 3: 141-144.

13. Ghareeb, K. and J. Bohm. 2009. Stress indicators to pre-slaughter broiler chickens fed diets supplemented with a synbiotic. International Journal of Biological Science, 8: 621-625.

14. Haghighi, H.R., J. Gong, C.L. Gyles, M.A. Hayes, H. Zhou, B. Sanei, J.R. Chambers and S. Sharif. 2006. Probiotics stimulate production of natural antibodies in chickens. Clinical and Vaccine Immunology, 13: 975-980.

15. Ibrahim, D.K., E.H. Al-Mashhadani and K. Al-Bandr. 2010. Effect of supplementation different levels of chromium yeast to diet on broiler chickens on some physiological traits. Pakistan Journal of Nutrition, 9: 942-949.

16. Kannan, M., R. Karunakaran, V. Balakrishnan and T.G. Prabhakar. 2005. Influence of prebiotics supplementation on lipid profile of broilers. International Journal of Poultry Science, 4: 994-997.

17. Katharina, E. Scholz-Ahrens, P. Ade, B. Marten, P. Weber, W. Timm and Y. Ail, C. Gluer and J. Schrezenmeir. 2007. Prebiotics, probiotics and synbiotics effect mineral absorption, bone mineral content and bone structure. American Journal of Nutrition, 137: 838-846.

18. Khosravi, A., F. Boldaji, B. Dastar and S. Hassani. 2008. The use of some feed additives as growth promoter in broilers nutrition. Internatinal Journal of Poultry Science, 7: 1095-1099.

19. Li, X.L., X.S. Piao, S.W. Kim, P. Liu, L. Wang, Y.B. Shen, S.C. Jung and H.S. Lee. 2017. Effects of chito-oligosaccharide supplementation on performance, nutrient digestibility, and serum composition in broiler chickens. Poultry Science, 86: 1107-1114.

20. Mountzouris, K.C., P. Tsirtsikos, E. Kalamara, S. Nitsch, G. Schatzmayr and K. Fegeros. 2007. Evaluation of the efficacy of a probiotic containing lactobacillus, bifidobacterium, entrococcus and pediococcus strains in promoting broiler performance and modulating cecal micro flora composition and metabolic activities. Poultry Science, 86: 309-317.

21. Mutus, R., N. Kocabagli, M. Alp, N. Acar, M. Eren and S.S. Gezen. 2006. The effect of dietary probiotic supplementation on tibial bone characteristics and strength in broilers. Poultry Science, 85: $1621-1625$.

22. NRC. 1994. Nutrition requirements of poultries, National Academy Press, Washington, D.C. 
$\omega$. اثرات افزودنىهاى خوراكى بر شاخصهاى بيوشيميايى و ايمونولوزيك خون و عملكرد بلدرجينهاى زاينى

23. Ozduven, M.L., H.E. Samli, A.A. Okur, F. Koc, H. Akyurek and N. Senkoylu. 2009. Effects of mannanoligosaccharide and/or organic acid mixture on performance, blood parameters and intestinal micro biota of broiler chicks. Italian Journal of Animal Science, 8: 595-602.

24. Paryad, A. and M. Mahmoudi. 2008. Effect of different levels of supplemental yeast (saccharomyces cerevisiae) on performance, blood constituents and carcass characteristics of broiler chicks. African Journal of Agricultural Research, 3: 835-842.

25. Riad Sosan, A., H.M. Safaa, Fatma, R. Mohamed, Salwa, S. Siam and Hanan A. El-Minshawy. 2010. Influence of probiotic, prebiotic and/or yeast supplementation in broiler diets on the productivity, immune response and slaughter traits. Journal of Animal and Poultry Production 1: 45-60.

26. Sahin, T., I. Kaya, Y. Unal and D.A. Elmali. 2008. Dietary supplementation of probiotic and prebiotic and prebiotic combination (combiotic) on performance, carcass quality and blood parameters in growing quails. Journal of Animal and Veterinary Advances, 7: 1370-1373.

27. Sarica, S., M. Corduk, G.F. Yarim, G. Yenisehirli and U. Karatas. 2009. Effects of novel feed additives in wheat based diets on performance, carcass and intestinal tract characteristics of quail. South African Journal of Animal Science, 39: abstract.

28. SAS institute. 2001. SAS user's Guide: Statistic. Version 8.2, SAS Institute lnc. CARY, NC, USA.

29. Strompfova, V., M. Marcinakova, S. Gancarcikova, Z. JonecOova, L. Scirankova, P. Guba, J. Koscova, K. Boldizarova and A. Laukova. 2005. New probiotic strain lactobacillus fermentum AD1 and its effect in Japanese quail. Veterinary Medicine-Czech, 50: 415-420.

30. Tuncay, T. and Memis, B. 2017. Effects of dietary addition of synbiotic on the performance, carcass traits and serum parameters of Japanese quails. Brazilian Journal of Animal Science, 46: 805-813.

31. Yunqin, C., Z. Xiaojin, P. Baishen, J. Xuejuan, Y. Haili, C. Bin, Z. Yunzeng, G. Junbo and C. Haozhu. 2010. A modified formula for calculating low-density lipoprotein cholesterol values. Lipids in Health and Disease, 9: 52. 


\title{
Effects of Feed Additives on Biochemical and Immunological Indices of Blood and Performance of Japanese Quails (Coturnix coturnix Japonica)
}

\section{Tohid Vahdatpour}

Assistant Professor of Physiology, Faculty of Animal and Veterinary Sciences, Shabestar Branch, Islamic Azad University, Shabestar, Iran, (Corresponding author: vahdatpour@iaushab.ac.ir)

\begin{abstract}
The purpose of this study was to compare effects of the different types of feed additives consumption including probiotics, prebiotics and synbiotics in Japanese quails. A total of 384 Japanese quail chicks were randomly assigned to 8 treatments with 4 replicates and 12 birds per replicate (cage). The experimental diets (treatments) were included: Basal diet without additive (control) and protexin $0.2 \mathrm{~g} / \mathrm{kg}$ (probiotic), Yeast $2 \mathrm{~g} / \mathrm{kg}$ (probiotic), Fermacto $1.6 \mathrm{~g} / \mathrm{kg}$ (prebiotic), Tepax $1 \mathrm{~g} / \mathrm{kg}$ (prebiotic), Biomin IMBO $1 \mathrm{~g} / \mathrm{kg}$ (synbiotic), Protexin $0.1+$ Fermacto $0.8 \mathrm{~g} / \mathrm{kg}$ (synbiotic), Yeast 1+Tepax $0.5 \mathrm{~g} / \mathrm{kg}$ (synbiotic) which were added to the basal diet. feed intake and body weight was higher $(\mathrm{P}<0.05)$ in quail fed detail containing additives.. The best feed conversion ratio were observed in quails fed diets containing tepax, yeast, biomin IMBO and fermacto $(\mathrm{P}<0.05)$. The use of additives affected the blood glucose, albumin, globulin and immunoglobulins $A$ and $G$ levels $(P<0.05)$. In the laying birds at the early stage of laying, the amount of blood triglycerides increased with diets containing synbiotic additives $(\mathrm{P}<0.01)$ The LDL level increased in females fed additive with exception of tepax and yeast+tepax $(\mathrm{P}<0.01)$. In male quails fed with the diet containing of the additives, the concentration of immunoglobulin $\mathrm{M}$ increased and $\mathrm{HDL}$ level decreased $(\mathrm{P}<0.05)$. The use of synbiotics and prebiotics improved the growth performance and increased blood albumin to globulin $(\mathrm{A} / \mathrm{G})$ ratio as an index of osmotic pressure in the blood. It is possible to use feed additives particular synbiotics while maintaining and improving the health of quails for organic meat and eggs production without the use of vaccines and antibiotics.
\end{abstract}

Keywords: Probiotic, Prebiotic, Synbiotic, Blood, Poultry 